Contributions to Mineralogy and Petrology COMIPE26

\title{
Laser Ablation ICPMS study of trace element partitioning between plagioclase and basaltic melts: an experimental approach
}

\author{
Mario Aigner-Torres ${ }^{1 *}$, Jon Blundy ${ }^{2}$ Peter Ulmer ${ }^{1}$, Thomas Pettke ${ }^{1+}$
}

\author{
${ }^{1}$ Institute of Mineralogy and Petrography, Swiss Federal Institute of Technology, ETH Zentrum NO, 8092 Zürich, \\ Switzerland \\ ${ }^{2}$ CETSEI, Department of Earth Sciences, University of Bristol, Wills Memorial Building, Bristol BS8 1 RJ, UK
}

\begin{abstract}
*Present address: Department of Petroleum Engineering, University of Campinas (DEP-FEM-UNICAMP), 6122
Campinas, SP 13083-970, Brazil

+Present address: Institute of Geological Sciences, University of Bern, Baltzerstrasse 1+3, CH-3012 Bern,

Switzerland
\end{abstract}

Corresponding author: mario@dep.fem.unicamp.br

Version: November 19, 2006 


\begin{abstract}
Plagioclase-melt partition coefficients (D) for 34 trace elements at natural concentration levels were determined experimentally in a natural MORB composition at atmospheric pressure using thin Pt-wire loops. Experiments were carried out at three temperatures $\left(1220,1200\right.$, and $\left.1180^{\circ} \mathrm{C}\right)$, and at three different oxygen fugacities $\left(f \mathrm{O}_{2}=\mathrm{IW}\right.$, QFM, air) in order to assess the effect of $f \mathrm{O}_{2}$ on the partitioning of elements with multiple valence (Fe, Eu, Cr). Run products were analyzed by laser-ablation ICP-MS. Most trace element D's increase slightly as temperature decreases, except for $\mathrm{D}_{\mathrm{Zr}}, \mathrm{D}_{\mathrm{Fe}}, \mathrm{D}_{\mathrm{Eu}}$ and $\mathrm{D}_{\mathrm{Cr}}$ that vary systematically with $f \mathrm{O}_{2}$. Applying the Lattice Strain Model to our data suggests the presence of $\mathrm{Fe}^{2+}$ entirely in the octahedral site at highly to moderate reducing conditions, while $\mathrm{Fe}^{3+}$ was assigned wholly to the tetrahedral site of the plagioclase structure. Furthermore, we provide a new quantitative framework for understanding the partitioning behaviour of Eu, which occurs as both $2+$ and $3+$ cations, depending on $f \mathrm{O}_{2}$ and confirm the greater compatibility of $\mathrm{Eu}^{2+}$, which has an ionic radius similar to $\mathrm{Sr}$, relative to $\mathrm{Eu}^{3+}$ in plagioclase and the higher $\mathrm{Eu}^{2+} / \mathrm{Eu}^{3+}$ under reducing conditions. For petrogenetic basaltic processes, a combined fractionation of $\mathrm{Eu}^{2+}-\mathrm{Sr}$ and $\mathrm{Fe}-\mathrm{Mg}$ by plagioclase has considerable potential as an oxybarometer for natural magmatic rocks.
\end{abstract}

Key words: trace elements-melting experiments-plagioclase-LA-ICPMS

\title{
1 Introduction
}

Mineral-melt trace element partition coefficients (D) are widely used in modeling of magmatic processes. In order to select the appropriate D for a particular magmatic problem it is essential to understand how D's vary with intensive parameters, such as pressure, temperature and $f \mathrm{O}_{2}$, as well as with composition. Plagioclase with its wide occurrence as a rock-forming mineral and its slow rate of intracrystalline diffusion (Grove et al., 1984; Morse, 1984) make it ideally suited to reconstructing the trace element content of the melts from which it grew, provided that appropriate trace element D's are available. Of particular interest are $\mathrm{Mg}$ and Fe, which occur as minor or trace elements in plagioclase and therefore have the potential to reveal the evolution of $\mathrm{Mg} / \mathrm{Fe}$ ratios in evolving magma. Similarly, $\mathrm{Fe}$ and Eu occur as both $2+$ and 3+ ions in magmas and $\mathrm{D}_{\mathrm{Fe}}$ and $\mathrm{D}_{\mathrm{Eu}}$ can be used to constrain the redox state of a magma. There are various natural and experimental studies in the literature where contents of certain trace elements in plagioclase have been routinely reported by microanalytical techniques (e.g. Phinney, 1994; Peters et al., 1994; Wilke and Behrens, 1999; Blundy, 1997; Simon et al., 1994). There are, however, only few experiments have been carefully designed and analyzed for measurements of a large number of trace elements (e.g. Bindeman et al., 1998). In this study we report a series of experiments performed at high temperatures and varying $f_{2}$ using a natural plagioclase-phyric basalt starting material. Laser ablation inductively coupled plasma mass spectrometer was used to analyze the run products for a large number of trace elements.

\section{Experimental and Analytical Procedures}

\subsection{Starting material}


A single starting material (ALV-3352-7) was used for all experiments. ALV-3352-7 is a natural, glassy and sparsely phyric pillow bud collected by the submersible Alvin from the Moai lava flow on the South East Pacific Rise at $18^{\circ} 110$ (Sinton et al., 1999). It consists of a large amount of fresh glass, up to $10 \%$ phenocrysts of plagioclase, with minor olivine and traces of spinel. The freshest parts of sample ALV-3352-7 were reduced to powder by grinding aliquots of representative mechanical splits. Samples were then finely crushed in an agate mortar under acetone. Complete chemical analysis of ALV-3352-7, including trace elements, can be found in Table 1.

\subsection{Experimental techniques}

For each experiment approximately $50 \mathrm{mg}$ of ALV-3352-7 powder was sintered onto a loop of $0.05 \mathrm{~mm}$ diameter platinum wire for no longer than 15 minutes. No pre-saturation of Pt with iron was employed, since the effective thickness of the Pt-wire minimized sample iron loss. The Pt-wire loop was suspended in the hot spot of a Gero 1-atm vertical gas-mixing furnace. Temperature was measured by a type $\mathrm{S}\left(\mathrm{Pt}_{90}-\mathrm{Rh}_{10}\right)$ thermocouple located just above the sample and a second, type $\mathrm{B}\left(\mathrm{Pt}_{94} \mathrm{Rh}_{6}-\mathrm{Pt}_{70} \mathrm{Rh}_{30}\right)$ thermocouple located in between the heating elements to control potential thermocouple poising in reducing atmosphere inside the furnace. The thermocouple was calibrated against the melting point of gold $\left(1064^{\circ} \mathrm{C}\right)$ and deviations are on the order of $\pm 2^{\circ} \mathrm{C}$. Oxygen fugacity was controlled by $\mathrm{H}_{2} / \mathrm{CO}_{2}$ gas mixture regulated by two Tylan mass flow controllers and calibrated in the hot spot of the furnace by determining the iron-wüstite and $\mathrm{Ni}-\mathrm{NiO}$ equilibria at $1200^{\circ} \mathrm{C}$, with an error estimated at $\pm 0.1 \log$ unit. Gas flow rates were maintained constant at $0.5 \mathrm{~cm}^{3} / \mathrm{s}$ for the $4.5 \mathrm{~cm}$ diameter furnace tube. This is sufficient to fix $f \mathrm{O}_{2}$ while minimizing the extent of sodium loss from the charge. Since plagioclase is a difficult mineral to nucleate and grow experimentally, it took several trial and error experiments to optimize the technique to grow homogeneous crystals sufficiently large for LA-ICP-MS analysis (> $40 \mu \mathrm{m}$ diameter). The experimental charges were initially held slightly above their liquidus for a certain time (typically 2 hours), allowing redox equilibration with the melt without completely destroying all plagioclase nuclei. They were subsequently cooled at a constant rate to the final run temperature, where they were left to equilibrate. Total run durations were up to about one week. Cooling rates varied from $1{ }^{\circ} \mathrm{C} / \mathrm{min}$ down to $1^{\circ} \mathrm{C} / \mathrm{hr}$ until reaching the final experimental temperature. Scatter around the values of some of the measured D's may be related to these cooling rate variations, and consequently to kinetic effects. Normally, our averaged partition coefficients (D's) within a certain run show less variation than D's averaged between charges with different cooling rates. Samples were drop-quenched into water by fusing the fine Pt suspension wire, and the quenched charges were mounted in an epoxy resin holder and polished sections made for petrographic and analytical analysis. Details of the experimental conditions, cooling history and resulting phase assemblage for representative runs are summarized in Table 2.

\subsection{Iron and Sodium loss}

The extent of $\mathrm{Fe}$ and $\mathrm{Na}$ loss in experiments at one atmosphere in gas mixing furnaces is a long-standing problem in experimental petrology and some alternative approaches have been used including pre-saturation of the Pt-wire (see Borisov and Jones, 1999; Tormey et al., 1987; Grove, 1981, and references therein). Because of the use of very thin Pt-loops with high average melt/loop mass ratio, Fe loss was comparable to the pre-saturation techniques, being up to 
$12 \%$ relative for experiments performed at the IW buffer at a moderate cooling rate. Fe loss is less at higher $f_{2}$. Sodium loss on the other hand, still poses serious problems under the 1-atm experiments reaching in the present experiments nearly $40 \%$ in the worst case. Sodium loss is thought to depend on $f \mathrm{O}_{2}$, temperature, run duration, size of sample material, gas flow rate and bulk chemical composition (see Tormey et al., 1987). Our very low $f \mathrm{O}_{2}$ runs shown the strongest increase in volatilization of $\mathrm{Na}$ (Table 2). This is consistent with Phinney (1992), who reported up to $60 \% \mathrm{Na}$ loss under similar experimental conditions. One possible side effect of this combined Fe and $\mathrm{Na}$ loss is to raise the liquidus temperature, enhancing the crystallization of plagioclase from 4 to $9 \%$ with increasing run duration from 97 to 166 hours associated with an increased Na- and Fe-loss from 10.6/1.2 wt.\% to 14.5/5.6 wt.\%. This is evident from Runs 25 and 34 conducted at the same isotherm $\left(1180^{\circ} \mathrm{C}\right)$ with different cooling rates.

\subsection{Electron Microprobe Analysis (EMP)}

Major and minor elements were analyzed with a SX100 Cameca electron microprobe at the Institute of Petrology, University of Vienna. An accelerating potential of $15 \mathrm{kV}$ was used for all analyses. For glass analysis the beam current was $10 \mathrm{nA}$, defocused to $10 \mu \mathrm{m}$ diameter. A $20 \mathrm{nA}$ focused beam was used for mineral analyses. Counting times for all phases were 20s peak and 10s background, except for $\mathrm{Na}$ and $\mathrm{K}$ in glass (10s peak $/ 5 \mathrm{~s}$ background) and $\mathrm{Fe}, \mathrm{Mg}, \mathrm{Ti}$ and $\mathrm{Mn}$ in plagioclase - from 20 to 50s peak, in order to improve the counting statistics, which are 1-3\% relative. Calibrations were performed using different natural and synthetic phases as standards for both minerals and glasses. A natural augite crystal was measured as a secondary standard and its $1 \sigma$ standard deviations were, in wt $\%$ : $0.26\left(\mathrm{SiO}_{2}\right), 0.03\left(\mathrm{TiO}_{2}\right), 0.04\left(\mathrm{Al}_{2} \mathrm{O}_{3}\right), 0.06(\mathrm{FeO}), 0.02(\mathrm{MnO}), 0.07(\mathrm{MgO}), 0.09(\mathrm{CaO})$, and $0.05\left(\mathrm{Na}_{2} \mathrm{O}\right) . \mathrm{A}$ labradorite from Lake County, Oregon, was analyzed periodically to check for consistency, and yielded relative precisions of $\pm 5 \%$ for $\mathrm{FeO}$ and $\pm 7 \%$ for $\mathrm{MgO}$. Analysis of other standards were within $2 \sigma$ of known values. Average error in total $\mathrm{FeO}\left(\mathrm{FeO}_{\mathrm{t}}\right)$ and $\mathrm{MgO}$ content of plagioclase due to analytical uncertainties are both about $0.02 \mathrm{wt} \%$ (1 $\sigma)$. These are in good agreement with errors averages related to compositional heterogeneity in run charges. PAP correction procedures were used to convert specimen/standard intensity ratios into concentrations.

\subsection{Laser ablation ICP-MS (LA-ICPMS)}

LA-ICPMS analyses were performed at the Institute of Isotope Geochemistry and Mineral Resources (ETH-Zürich) using a 193 nm ArF excimer laser system (Günther et al., 1997) combined with an ELAN 6100 quadrupole ICP-MS. The NIST SRM610 glass was used to calibrate analytical sensitivities. Internal standardization required for element concentration calculations employed major element concentrations as determined by EPMA. Operating conditions were very similar to those reported in Pettke et al. (2004). Embedded, polished capsules were loaded with the external standard in a $5 \mathrm{~cm}^{3}$ ablation cell and put on the stage of a modified petrographic microscope operated in reflected light mode, allowing perfect positioning of the laser beam and selection of the appropriate spot size. Because transmitted light observation cannot be used for embedded capsules, any melt inclusions in the minerals cannot be optically identified. The acquisition of transient signals measured with $10 \mathrm{~ms}$ dwell time per isotope; however, allows the identification of such melt inclusions in the analytical signal. Thus, the raw data were carefully screened for such inclusion signals and these were then manually removed. ICPMS operating conditions were daily 
optimized on SRM610 glass, ensuring low element-oxide production rates ( $\mathrm{Th} / \mathrm{ThO}$ tuned to $>0.2 \%$ ), robust plasma conditions and maximal signal-to-noise ratios for the isotopes of interest. Robust plasma conditions allow non-matrix matched calibration of LA-ICPMS signals (reviewed in Pettke, 2006); hence, the SRM610 glass is perfectly suitable for calibration (see also Heinrich et al., 2003). Two standard deviation uncertainties on shot-to-shot reproducibilities are typically $2-5 \%$ on silicate phases unless signals are close to the respective detection limits (LOD), where counting statistics uncertainties may increase the overall uncertainty up to a few tens of percent. Data reduction was performed using the Lamtrace program, following principles outlined in Longerich et al. (1996). Each shot was filtered using the individual, shot-specific LOD based on the 3 sigma criterion (Longerich et al., 1996). It is worth noting that the LOD increases for any given element with decreasing pit size. Given the often small grains in our reaction products, we thus rarely obtained significant element concentrations for some of the elements analyzed.

\section{Results}

\subsection{Overview of run products and data}

Plagioclase is the liquidus phase in all of the experiments, irrespective of $f \mathrm{O}_{2}$. The experimental runs produced homogeneous, euhedral to subhedral plagioclase crystals up to several hundred $\mu \mathrm{m}$ in length (Figure 1). The selected 10 runs shown in Table 2 have high glass contents $(>80 \%)$, giving large areas for analysis. All run products were very similar at the highest isotherm, but slight differences among phase appearance due to different oxygen fugacities and possibly cooling rates were observed. In addition to plagioclase and glass, a few traces of olivine and clinopyroxene appear. Spinel is a common phases at oxidizing conditions, being usually subhedral and showing sieve-texture within plagioclase crystals. Thus, at least for some runs, spinel could have appeared on the liquidus prior to the formation of plagioclase. The first oxide phase to crystallize is Fe-rich spinel with $65-68 \% \mathrm{Fe}_{2} \mathrm{O}_{3}, 5 \%$ $\mathrm{FeO}, 0.7 \% \mathrm{TiO}_{2}, 17-18 \% \mathrm{MgO}$, and $7-9 \% \mathrm{Al}_{2} \mathrm{O}_{3} . \mathrm{Cr}_{2} \mathrm{O}_{3}$ decreases with temperature from 0.65 to $0.04 \mathrm{wt} \%$. The chemical variation in the other phases is not further considered here. Major and trace element analysis of plagioclases and glasses are listed in Tables 3 and Tables 4, respectively. All the plagioclases from this study are anorthite rich and exhibit a very narrow range in composition (73-79 mol\%, Table 2). Major element homogeneity of different synthesized plagioclase crystals were checked by performing line profiles and, as in Phinney (1992), large crystals were used in order to avoid the possible effects of secondary fluorescence during EMP analyses. Calculated average relative standard deviations (RSD) on multiple analyses were better than $1 \%$ for $\mathrm{SiO}_{2}$ and $\mathrm{Al}_{2} \mathrm{O}_{3}$, $1.5 \%$ for $\mathrm{CaO}$, and $5 \%$ for $\mathrm{Na}_{2} \mathrm{O}$. For $\mathrm{FeO}$ and $\mathrm{MgO}$ variations are better than $20 \%$ and $10 \%$, respectively. The minor elements $\mathrm{TiO}_{2}, \mathrm{MnO}$ and $\mathrm{K}_{2} \mathrm{O}$ have very large variations due to their low content and poor accuracy by EMP. Trace element concentrations in plagioclases have average RSD's on multiple analyses that vary depending on the element in question. For $\mathrm{Sr}$, maximum averages are close to $10 \%$, but for $\mathrm{Cr}$ and other highly incompatible elements (e.g. heavy rare earth elements, HREE), the associated RSD average can be much higher, since these elements are essentially at the limits of detection of the LA-ICP-MS. Calculated average RSD's from multiple analyses for both major and trace elements in glass run products are typically much more homogeneous when compared with plagioclases (Tables 3 and 4). This can be attributed to the higher concentrations of most of the elements measured in glasses and due to the larger laser pit sizes $(80 \mu \mathrm{m})$, allowing better constrained measurements and LOD. 
Homogeneity of the newly grown plagioclase crystals alone does not guarantee that near equilibrium conditions were attained during the experiments. The lack of zoning is a further indication that at least steady state conditions were achieved during the run time. Classical reversal experiments could not be performed because it resulted to be impossible to grow homogenous and large enough crystals for EMP and LA-ICP-MS analysis by forward melting experiments. Only by slow cooling from just above the liquidus where only a minimum of nuclei survived resulted such crystals. As a additional test for the attainment of equilibrium we present a comparison of the $\mathrm{CaO} /\left(\mathrm{Na}_{2} \mathrm{O}+\mathrm{K}_{2} \mathrm{O}\right)$ partitioning between homogenous, euhedral plagioclase and quenched liquid (glass) from this study and literature data obtained for basaltic systems at 1 bar (Bender et al., 1978; Grove \& Bryan, 1983; Tormey et al., 1987; Grove et al., 1990; Bartels et al., 1991; Baker et al., 1994; Yang et al., 1996; Thy et al., 1999; Sano et al., 2001). The diagram (Figure 2) reveals two important observations: (i) The data points from our experiments plot within range defined by the large number of comparable experiments from literature, except (ii) the three runs at low $\mathrm{fO}_{2}$ and long run duration (\#16,17, and 35, open circles) that suffered 33-40\% relative $\mathrm{Na}_{2} \mathrm{O}$-loss. These data point plot towards high $\mathrm{CaO} /\left(\mathrm{Na}_{2} \mathrm{O}+\mathrm{K}_{2} \mathrm{O}\right)$ values for the liquid phase because their sodium values are low. This behavior indicates that plagioclase grew rather early in the experiments and did not adjust their composition upon loss of sodium during the late stage of the experiments. The arrows indicate the shift of these samples when the Na-loss in the coexisting liquids are adjusted using the results from the least squares regression; after correction all three data point perfectly plot within the range defined by our other samples and the range covered by the literature data. This is consistent with very slow coupled CaAl-NaSi diffusion in plagioclase that does no exceed $10^{-18} \mathrm{~cm}^{2} / \mathrm{sec}$ for plagioclase of $\mathrm{An}_{80}$ at $1200^{\circ}$ C. (e.g. Grove et al.; 1984, Morse, 1984). Therefore, re-equilibration of early grown crystals is inhibited, except for the outermost rim that could not be quantitatively analyzed. In conclusion, all but the three experiments at low $f \mathrm{O}_{2}$ show $\mathrm{Ca}-\mathrm{Na}-\mathrm{K}$ partitioning consistent with a large number of 1 bar experiments from literature; the three samples that suffered large sodium loss did not re-equilibrate with the changing liquid composition (for sodium calcium) but records the equilibrium partitioning acquired in the early stages of the experiments when the crystals grew. Taking this shortcoming into consideration we have used all reported data for subsequent discussion of the trace and minor element partitioning behavior.

\subsection{Partition coefficients}

D's for each experimental run, calculated from LA-ICP-MS analysis (Table 4) are summarized in Table 5. Figure 3 shows D-values for different groups of elements according to their experimental temperatures and $f \mathrm{O}_{2}$. We also compared the experimental D's with those derived from plagioclase and glass analysis of the natural sample ALV3352-7 analyzed by the same LA-ICP- MS technique (Table 1).

\subsubsection{Majors elements ( $\mathrm{Si}, \mathrm{Al}, \mathrm{Ca}, \mathrm{Na})$}

The concentrations of $\mathrm{CaO}, \mathrm{Al}_{2} \mathrm{O}_{3}, \mathrm{SiO}_{2}$, and $\mathrm{Na}_{2} \mathrm{O}$, which represent the main solid solution components in plagioclase, give very stable D values—calculated from microprobe analyses in Table 3. Averages for compatible

and near-compatible elements, $\mathrm{D}_{\mathrm{Si}} 0.97 \pm 0.02, \mathrm{D}_{\mathrm{Al}} 2.07 \pm 0.10$, and $\mathrm{D}_{\mathrm{Ca}} 1.26 \pm 0.03$, are independent of temperature and oxygen fugacity. Only $\mathrm{D}_{\mathrm{Na}}$ shows a larger variation $1.34 \pm 0.30$ —due to the likely coupled effect of $f \mathrm{O}_{2}$ and 
volatilization. Natural sample ALV3352-7, which is unlikely to have suffered Na loss to the same extent, has much lower $\mathrm{D}_{\mathrm{Na}}(0.806)$.

\subsubsection{Transition metals ( $\mathrm{Sc}, \mathrm{Cr}, \mathrm{Mn}, \mathrm{Fe})$ and $\mathrm{Mg}$}

D's for Mg and transition metals increase with decreasing temperature ( $\mathrm{Sc}, \mathrm{Mn}, \mathrm{Fe}$ ) or are nearly constant $(\mathrm{Mg}, \mathrm{Cr}$ ). As expected $\mathrm{D}_{\mathrm{Fe}}$ increases strongly with increased $f \mathrm{O}_{2}$ (Phinney, 1992; Wilke \& Behrens, 1999). A similar, but less marked increase is seen for $\mathrm{D}_{\mathrm{Cr}}$. $\mathrm{D}_{\mathrm{Sc}}$ shows much smaller variations with $f \mathrm{O}_{2}$, in accordance with its single valence state. No set of run experiments performed at the same temperature have a complete data set for Sc values under all three $f \mathrm{O}_{2}$ (see Table 5); however, at $1200^{\circ} \mathrm{C} \mathrm{D}_{\mathrm{Sc}}$ averages 0.016 , which is exactly the same averaged value for both runs under more reducing conditions (IW) across the two highest isotherms $\left(1220\right.$ and $\left.1200^{\circ} \mathrm{C}\right)$. A strong increase of $\mathrm{D}_{\mathrm{Sc}}$ with decreasing temperature occurs at oxidizing conditions, from $0.035\left(1220^{\circ} \mathrm{C}\right)$ up to $0.114\left(1180^{\circ} \mathrm{C}\right)$; see Figure 3. Sample ALV-3352-7 with $\mathrm{D}_{\mathrm{Sc}}$ of 0.021 is very close to the values at $1180^{\circ} \mathrm{C}$ and $\mathrm{QFM}$ conditions; i.e. runs $25(0.025)$ and $34(0.021)$, respectively. Values of $\mathrm{D}_{\mathrm{Cr}}$ are quite low with large uncertainty; however, excluding run $25\left(1180^{\circ} \mathrm{C}\right), \mathrm{D}_{\mathrm{Cr}}$ increases from 0.019 to 0.064 with increasing $f \mathrm{O}_{2}$ (Figure 3), possibly reflecting a smooth variation in the ratio of $\mathrm{Cr}^{2+}$ to $\mathrm{Cr}^{3+}$. Average $\mathrm{D}_{\mathrm{Cr}}$ close to IW conditions at 1200 and $1220^{\circ} \mathrm{C}(0.038)$ matches $\mathrm{D}_{\mathrm{Cr}}$ in $\mathrm{ALV}$ 3352-7 (0.035). In air $\mathrm{D}_{\mathrm{Mn}}$ increases with decreasing temperature-from $0.034\left(1220^{\circ} \mathrm{C}\right)$ to $0.184\left(1180^{\circ} \mathrm{C}\right)$, and increases sharply in the $1180^{\circ} \mathrm{C}$ set of experiments: from 0.026 (QFM) to 0.184 (air). It is uncertain from our data if this increase is related to a departure from the dominant species $\mathrm{Mn}^{2+}$. Natural sample ALV-3352-7 has the same $\mathrm{D}_{\mathrm{Mn}}$ value (0.029) as run 31 at $1220^{\circ} \mathrm{C}$ close to the QFM buffer. $\mathrm{D}_{\mathrm{Fe}}$ values displayed in Figure 3 show clearly both the effects of temperature (parallel trends) and oxygen fugacity (vertical trends). The strongest effect of temperature can be seen at air conditions, where $\mathrm{D}_{\mathrm{Fe}}$ increases with decreasing temperature; $0.237\left(1220^{\circ} \mathrm{C}\right)-0.339\left(1200^{\circ} \mathrm{C}\right)-$ $0.665\left(1180^{\circ} \mathrm{C}\right)$. However, at both IW and QFM conditions the influence of temperature is not apparent (Figure 3). These results are in agreement with the previous studies of Sato (1989) and Phinney (1992) at similar temperatures. Thus, $\mathrm{D}_{\mathrm{Fe}}$ is tightly constrained at $0.0267 \pm 0.0047$ under highly reducing conditions, where it is independent of temperature. In contrast $\mathrm{D}_{\mathrm{Fe}}$ at air conditions varies greatly with temperature- reflecting the redox change from $\mathrm{Fe}^{2+}$ to $\mathrm{Fe}^{3+}$. Sample ALV-3352-7 with $\mathrm{D}_{\mathrm{Fe}}$ of 0.046 is situated between conditions intermediate to the IW and QFM buffers. $\mathrm{D}_{\mathrm{Mg}}$ is well constrained with an overall average of $0.043 \pm 0.009$, showing neither great variation with temperature nor oxygen fugacity. Some subtle temperature effects at air conditions are observed; from 0.037 $\left(1220^{\circ} \mathrm{C}\right)$ down to $0.053\left(1180^{\circ} \mathrm{C}\right)$ as also reported in Bindeman et al. (1998). Peters et al. (1995) and Simon et al. (1994) reported partition coefficients of 0.035 and 0.039 for $\mathrm{D}_{\mathrm{Mg}}$ using CAI bulk compositions. Using a similar bulk composition to this study, Sato (1989) and Phinney (1992) report values for $\mathrm{D}_{\mathrm{Mg}}$ of 0.043 at $1200^{\circ} \mathrm{C}$ and 0.044 at $1180^{\circ} \mathrm{C}$. Runs 29 (air at $1220^{\circ} \mathrm{C}$ ) and $31\left(\mathrm{QFM}\right.$ at $1200^{\circ} \mathrm{C}$ ) with $\mathrm{D}_{\mathrm{Mg}}$ values of 0.037 and 0.038 respectively, are close to 0.033 of natural sample ALV-3352-7.

\subsection{3 $\mathrm{Li}$ and LILE (K, Rb, $\mathrm{Sr}, \mathrm{Cs}, \mathrm{Ba}, \mathrm{Pb})$}

Large ion lithophile elements (LILE) consist of strong compatible ( $\mathrm{Sr}$ and $\mathrm{Pb}$ ) to moderately incompatible $(\mathrm{K}, \mathrm{Rb}$, $\mathrm{Ba}$ ) elements (Figure 3). Thermal dependence may be strong (K, $\mathrm{Pb}$ ), subtle (Ba), or practically absent $(\mathrm{Sr})$. $\mathrm{Li}, \mathrm{Rb}$ 
and Cs are highly variable and not well-constrained (Table 5). At air conditions, $\mathrm{D}_{\mathrm{K}}$ increases with decreasing temperature -0.169 at $1220^{\circ} \mathrm{C}$ to 0.245 at $1180^{\circ} \mathrm{C}$. Run no. $17\left(1200^{\circ} \mathrm{C} / \mathrm{IW}\right)$ is low compared to the general trend. Average $\mathrm{D}_{\mathrm{K}}$ calculated irrespective of temperature and $f \mathrm{O}_{2}$ is $0.205 \pm 0.048$. Pairs of glass/plagioclase in sample ALV3352-7 have $D_{K}$ of 0.127, which is quite low when compared to any experimental result; the nearest being run no. 29 at $1220^{\circ} \mathrm{C} /$ air $(0.169)$. $\mathrm{D}_{\mathrm{Sr}}$ is strongly compatible and very tightly constrained in our experiments- $1.60 \pm 0.1$ independent of oxygen fugacity and temperature, reflecting our narrow range of temperature, liquid and plagioclase composition, parameters well known to influence the partitioning of Sr (Blundy and Wood, 1991; Bindeman et al., 1998; Morse, 1984). For comparison the value of $\mathrm{D}_{\mathrm{Sr}}$ calculated for $\mathrm{An}_{77}$ at $1200^{\circ} \mathrm{C}$ using the model of Blundy and Wood (1991) is 1.66, in good agreement with the value determined here. $\mathrm{D}_{\mathrm{Ba}}$ is moderately incompatible with average values around $0.266 \pm 0.069$ independent of both temperature and $f \mathrm{O}_{2}$. There is a small increase in $\mathrm{D}_{\mathrm{Ba}}$ with decreasing temperature close to the QFM buffer; from $0.226\left(1220^{\circ} \mathrm{C}\right)$ up to $0.286\left(1180^{\circ} \mathrm{C}\right)$. Data for run 17 (IW) is unusually low compared to all other values. Run no. $29\left(1220^{\circ} \mathrm{C} / \mathrm{air}\right)$ has $\mathrm{D}_{\mathrm{Ba}}=0.213$, which is near the ALV-3352-7 $\mathrm{D}_{\mathrm{Ba}}$ value of 0.2095 . For comparison the value of $\mathrm{D}_{\mathrm{Ba}}$ calculated for $\mathrm{An}_{77}$ at $1200^{\circ} \mathrm{C}$ using the model of Blundy and Wood (1991) is 0.21, in excellent agreement with the value determined here. $\mathrm{D}_{\mathrm{Pb}}$ is compatible for almost the entire experimental range studied. Unfortunately, there is no complete set of values for $\mathrm{D}_{\mathrm{Pb}}$ for any one oxygen fugacity condition. One trend is discernible though; $\mathrm{D}_{\mathrm{Pb}}$ increases in air from $0.989\left(1220^{\circ} \mathrm{C}\right)$ to $2.72\left(1180^{\circ} \mathrm{C}\right)$, a pattern also observed in Bindeman et al. (1998). $\mathrm{D}_{\mathrm{Pb}}$ of 1.901 from sample ALV-3352-7 is only closest to run no. 31 at $1200^{\circ} \mathrm{C} / \mathrm{QFM}(1.59)$.

\subsubsection{Rare earths elements and $Y$}

$\mathrm{D}_{\mathrm{REE}}$ are reasonably constrained for the light REE (LREE), whereas Eu shows more complex behavior, due to its variable oxidation state. On the other hand, D values for middle and heavy REE ( $\mathrm{Sm}, \mathrm{Gd}, \mathrm{Tb}, \mathrm{Dy}, \mathrm{Ho}, \mathrm{Er}, \mathrm{Tm}, \mathrm{Yb}$, $\mathrm{Lu}$ ) are highly uncertain as their concentrations lie close to detection limits (Table 5). $\mathrm{D}_{\mathrm{La}}$ and $\mathrm{D}_{\mathrm{Ce}}$ have average values of $0.063 \pm 0.017$ and $0.046 \pm 0.009$, respectively. Natural sample ALV-3352-7 has $\mathrm{D}_{\mathrm{La}}$ of 0.056 , close to the average of runs 25 and $34\left(1180^{\circ} \mathrm{C} / \mathrm{QFM}\right) . \mathrm{D}_{\mathrm{Pr}}$ and $\mathrm{D}_{\mathrm{Nd}}$ show a greater variability than $\mathrm{D}_{\mathrm{La}}$ and $\mathrm{D}_{\mathrm{Ce}}$. Considering only the more robust subset of the data, with low standard deviations, average $\mathrm{D}_{\mathrm{Nd}}$ is values are around 0.04 , which is close to sample ALV-3352-7 value of 0.029. The exception is run 33 in air which has anomalously high $\mathrm{D}_{\mathrm{Pr}}$ and $\mathrm{D}_{\mathrm{Nd}}$. The reason for this is not known. $\mathrm{D}_{\mathrm{Y}}$ is consistently 0.008 , irrespective of temperature or $f \mathrm{O}_{2}$. $\mathrm{D}_{\mathrm{Y}}$ for sample ALV3352-7 is almost 10 times higher (0.070) than the experimental value. $\mathrm{D}_{\mathrm{Eu}}$ show clear trends of both effect of temperature and oxygen fugacity (Figure 3). With a reversed pattern to that seen in $\mathrm{D}_{\mathrm{Fe}}$ (Figure 3), the higher $\mathrm{D}_{\mathrm{Eu}}$ values appear under the most reducing conditions; IW - Figure 3. Notwithstanding the below-detection value for run $31\left(1200^{\circ} \mathrm{C} / \mathrm{air}\right)$ and the anomalously low value of run 17, $\mathrm{D}_{\mathrm{Eu}}$ averages 0.91 (IW), 0.14 (QFM) and 0.14 (air) independently of temperature. This reflects the well-established greater compatibility of $\mathrm{Eu}^{2+}$, which has an ionic radius similar to $\mathrm{Sr}$, relative to $\mathrm{Eu}^{3+}$ in plagioclase and the higher $\mathrm{Eu}^{2+} / \mathrm{Eu}^{3+}$ under reducing conditions. In a later section we will discuss the relative influences of crystal and melt composition, $f \mathrm{O}_{2}$ and temperature on the behavior of $D_{\mathrm{Eu}}$. At this point, however, we note that $\mathrm{D}_{\mathrm{Eu}}$ for natural sample ALV-3352-7 (0.21) is close to the run 28 $\left(1220^{\circ} \mathrm{C} / \mathrm{QFM}\right)$ value of 0.24 . 


\subsubsection{HFSE (Ti, Zr, Nb, Hf, Ta, Th, U)}

High field strength elements (HFSE) are highly incompatible in plagioclase. Except for $\mathrm{Ti}$ and $\mathrm{Zr}$, the data are highly variable and elements are at their detection limits (Table 5). $\mathrm{D}_{\mathrm{Ti}}$ shows temperature variations at air conditions (Figure 3) similar to those seen in other transition metals; i.e., $\mathrm{D}_{\mathrm{Ti}}$ increases with decreasing temperature- 0.034 $\left(1220^{\circ} \mathrm{C}\right)$ to $0.123\left(1180^{\circ} \mathrm{C}\right)$. Close to $\mathrm{QFM}, \mathrm{D}_{\mathrm{Ti}}$ averages $0.043 \pm 0.005$ being in close in agreement with the experiments of Peters et al. (1995), who point to the possible presence of small amounts of $\mathrm{Ti}^{3+}$ under these conditions. On the other hand, Phinney (1992) found no such variation in $\mathrm{D}_{\mathrm{Ti}}$ even with $f \mathrm{O}_{2}$ ranging over 13 orders of magnitude. Bindeman et al. (1998) reported an increase in $\mathrm{D}_{\mathrm{Ti}}$ with decreasing $\mathrm{X}_{\mathrm{An}}$. $\mathrm{D}_{\mathrm{Ti}}$ from run no. $17\left(1200^{\circ} \mathrm{C} / \mathrm{IW}\right)$ is very low (0.014) compared to both other runs under the same $f \mathrm{O}_{2}$ that average 0.0385. Natural sample ALV-3352$7 \mathrm{D}_{\mathrm{Ti}}$ is intermediate $(0.024)$ between these two values. $\mathrm{D}_{\mathrm{Zr}}$ shows the greatest variation in partition coefficients for plagioclases (Figure 3). Contrary to Ti, $\mathrm{D}_{\mathrm{Zr}}$ at air conditions decreases with decreasing temperature, from 0.032 $\left(1220^{\circ} \mathrm{C}\right)$ down to $0.009\left(1180^{\circ} \mathrm{C}\right)$. At both 1220 and $1200^{\circ} \mathrm{C}$ isotherms, $\mathrm{D}_{\mathrm{Zr}}$ is relatively constant at all oxygen fugacities - run no. $25\left(1180^{\circ} \mathrm{C} / \mathrm{QFM}\right)$ with $\mathrm{D}_{\mathrm{Zr}}$ of 0.003 is closest to sample ALV-3352- 7 (0.0025). The variability of $\mathrm{D}_{\mathrm{Zr}}$ in experiments run in air is strikingly similar to that for Fe (Figure 3), despite the fact that $\mathrm{Zr}$ is only known as $\mathrm{Zr}^{4+} . \mathrm{D}_{\mathrm{Ta}}$ increases with decreasing temperature (Figure 3); however, the experiments used to determine $\mathrm{D}_{\mathrm{Ta}}$ are all three at different $f \mathrm{O}_{2}$ conditions - 0.042 (1220/IW), 0.053 (1200/QFM), and 0.170 (1180/air). Natural sample ALV3352-7 has $\mathrm{D}_{\mathrm{Ta}}$ much higher (0.643) than any experimental run.

\section{Discussion}

Naturally occurring plagioclase can incorporate a wide range of elements and many geochemically important minor and trace elements (e.g. $\mathrm{Li}, \mathrm{K}, \mathrm{Sr}, \mathrm{Ba}$ ) are known to substitute for major divalent cations in the large octahedral Asite; however, a small number of elements (e.g. Ti, Zr) are thought to enter the tetrahedral site via coupled substitution by replacing Al. Others, such as $\mathrm{Mg}$ and $\mathrm{Fe}$ might be split between both A- and T-sites. Elements at very low concentrations are believed to partitioned into defect sites (e.g. Urusov and Dudnikova, 1998).

\section{1 $D$ and site occupancy}

The ideal formula of plagioclase represented by $\mathrm{AT}_{4} \mathrm{O}_{8}$, and with cation ordering in both $\mathrm{A}$ - and $\mathrm{T}$-sites, is rather complex. In previous studies, (see Bindeman and Davis, 2000, and references therein) various end-member plagioclases have been synthesized and demonstrate a wide range of possible substitution mechanisms for minor and trace elements in plagioclase; e.g. coupled A- and T-site substitutions, six- to nine-coordinated A-sites.

Stoichiometric deficiencies caused vacancy substitution on the A-site are thought to play an important role in plagioclases crystallizing from silica-rich melts (Longhi et al., 1976). Cation site occupancies of major elements in plagioclase (e.g. Si, Al, Ca, Na) are well established (e.g. Smith and Brown, 1988), and general consensus for the cation site-assignments for most of the minor and trace elements should be: $\mathrm{VIII}_{\mathrm{A}}$ : LILE (e.g., $\mathrm{K}^{+}$), $\mathrm{Na}^{+}, \mathrm{Ca}^{2+}$, transition metals (e.g., $\mathrm{Fe}^{2+}, \mathrm{Sc}$ ), $\mathrm{Mg}^{2+}, \mathrm{REE}^{3+} \mathrm{IV}_{\mathrm{T}}$ : transition metals (e.g., $\mathrm{Fe}^{3+}, \mathrm{Cr}^{3+}$ ), $\mathrm{Mg}^{2+}$, HFSE (e.g., $\mathrm{Ti}^{4+}, \mathrm{Zr} 4+^{2}$ ), $\mathrm{REE}^{3+}, \mathrm{Al}^{3+}, \mathrm{Si}^{4+}$. One the other hand, we can make no distinction between the different cavities in the A- and T- 
sites-i.e. A1, A2; T1O, T1m, T2O. Moreover, the site occupancies for some elements; e.g., the highly incompatible elements are particularly difficult to establish, since some of the elements shows heterovalent substitution (e.g. Fe and $\mathrm{Eu}$ ) and/or site splitting (e.g., $\mathrm{Mg}$ and $\mathrm{Fe}$ ). Figure 4 shows the relationship between ionic radius and several partition coefficients in terms of an Onuma-diagram (Onuma et al., 1968) for run no. $31\left(1200^{\circ} \mathrm{C} / \mathrm{QFM}\right)$. The partitioning behaviour of the divalent cations $\mathrm{Mg}^{2+}, \mathrm{Fe}^{2+}, \mathrm{Ca}^{2+}, \mathrm{Sr}^{2+}, \mathrm{Pb}^{2+}$ and $\mathrm{Ba}^{2+}$ can be described by a parabola with a maximum that corresponds to the size of the VIII-fold coordinated A-site in plagioclase (Blundy \& Wood, 1994). Relative to this curve, all large cations with 3+ (e.g. REE) or 4+ valence are displaced to lower D values, while alkali metals, $\mathrm{Li}, \mathrm{Na}, \mathrm{K}, \mathrm{Pb}$, describe a more open parabola, consistent with lower solution energies for $1+$ cations relative to higher valence cations of the same ionic radius (Blundy \& Wood, 1994, 2003a). On the other hand, small highly-charged ions $\left(\mathrm{Sc}^{3+}, \mathrm{Ti}^{4+}, \mathrm{Cr}^{3+}, \mathrm{Nb}^{5+}, \mathrm{Ta}^{5+}, \mathrm{Zr}^{4+}\right)$ deviate significantly from the A-site parabolae and appear to lie closer to the size of IV-coordinated T-site, occupied by $\mathrm{Al}^{3+}$ and $\mathrm{Si}^{4+}$ (Figure 4). There are some peculiarities, as in the case of $\mathrm{Eu}$ and $\mathrm{Fe}$ - both plotted as both 2+ and 3+ ionic radii. Eu is strongly affected by oxygen fugacity (see below) and shows its non-conformity within the LREE and Y trend. For Fe and Mg several authors, on the grounds of stoichiometry and experiments, have suggested tetrahedral occupancy (Bryan, 1974; Longhi et al., 1976; Meyer and Shibata, 1990; Sclar and Benimoff, 1980; Sclar and Kastelic, 1979; Zeng, 1985; Murakami et al., 1992; Wenk et al., 1973; Wenk and Wilde, 1973). Others showed that $\mathrm{Fe}^{2+}$ substitutes for the larger eight-coordinated A-sites as well, either by correlating ionic radius with D (Bindeman et al., 1998; Blundy, 1997) or by using different spectroscopy techniques (Schümann and Hafner, 1972; Hofmeister and Rossman, 1984). Generally, our data at the QFM buffer for Fe and Mg seems to plot well within the 2+ parabola for the VIII-fold Asite (Figure 4).

\subsection{Lattice Strain Model (LSM)}

Variation in pressure, temperature, $f \mathrm{O}_{2}$, composition, crystal chemistry and liquid structure might all affect plagioclase partition coefficients. Predictive models based on experimental studies for the partitioning of plagioclasemelt pairs for the highly incompatible elements (i.e., Fe, $\mathrm{Ti}$ and $\mathrm{Mg}$ ) have either shown strong partition coefficient relation to the liquid phase (e.g. Peters et al., 1995), or to the plagioclase composition (e.g. Bindeman et al., 1998). Additionally, in the case of partitioning of polyvalent cations (e.g. Fe, Eu), oxygen fugacity plays an important role (e.g. Phinney, 1992; Wilke and Behrens, 1999). Furthermore, Bindeman and Davis (2000); Bindeman et al. (1998) have shown for various trace elements that the plagioclase structure was primarily responsible for the difference in D's at different concentrations.

Blundy and Wood (1994, 2003b) have rationalized the partitioning behaviour of homovalent series of cations between plagioclase and melt in terms of a Lattice Strain Model (LSM) based on the Brice (1975) equation which relates the partition coefficient of element $i\left(\mathrm{D}_{\mathrm{i}}\right)$, with radius $\mathrm{r}_{\mathrm{i}}$, to that of an element $o\left(\mathrm{D}_{0}\right)$ which has the same ionic radius $r_{0}$ as the crystallographic site of interest, such as the plagioclase A-site: 


$$
D_{i}=D_{0} \exp \left(\frac{-4 \pi E N_{A}\left(\frac{r_{o}}{2}\left(r_{i}-r_{o}\right)^{2}+\frac{1}{3}\left(r_{i}-r_{o}\right)^{3}\right)}{R T}\right)
$$

Where $\mathrm{N}_{\mathrm{A}}$ is Avogadro's number, $E$ is the Young's Modulus of the site, $R$ is the gas constant and $T$ is in $\mathrm{K} . \mathrm{E}, \mathrm{r}_{0}$ and $\mathrm{D}_{0}$ can be obtained by fitting the experimental partitioning data for homovalent cation series to Equation (1).

Because of the rapid increase in apparent site Young's Modulus, E, with increasing cation charge and decreasing site dimensions (Blundy \& Wood, 2003a), this exercise is best confined to the large plagioclase A-site. In Figure 5a we show an Onuma diagram of partition coefficients for selected large divalent cations and REE at $1220^{\circ} \mathrm{C}$ and IW buffer. $\mathrm{Ba}, \mathrm{Sr}, \mathrm{Ca}$ and $\mathrm{Mg}$ lie along a smooth parabolic curves fitted as a function of their radii to Equation (1). Values of $\mathrm{D}_{0(2+)}, \mathrm{r}_{0(2+)}$ and $\mathrm{E}_{0(2+)}$ are displayed in Table 6, and are similar for all runs along a given isotherm. Individual experiments are consistent with those divalent elements occupying the A-site with optimal size $\mathrm{r}_{0(2+)}$ of 1.203-1.225 ̊. For comparison the calculated $\mathrm{r}_{0(2+)}$ for $\mathrm{An}_{77}$ plagioclase from Blundy \& Wood (2003b) is $1.214 \AA$. Our calculated $\mathrm{E}_{(2+)}$ values (Table 6) lie in the range 104-124 GPa, again in good agreement with the model value of Blundy \& Wood (2003b), 116 GPa.

We have also fitted 3+ parabolae to the partition coefficients of Y, La, Ce, Pr and Nd (Figure 5a; other $\mathrm{D}_{\mathrm{REE}}$ are too imprecise to be of use in fitting) to derive $\mathrm{E}_{(3+)}$ and $\mathrm{r}_{0(3+)}$ (Table 6). The fit parameters are subject to considerable uncertainty. However, fitted values of $\mathrm{E}_{(3+)}$ are in the range 172-296 GPa, compared to a model value of $210 \mathrm{GPa}$ (Blundy \& Wood, 2003b), and $\mathrm{r}_{0(3+)}$ are in the range 1.15-1.22 $\mathrm{\AA}$, compared to 1.185 $\AA$ for $\mathrm{An}_{77}$ (Blundy \& Wood, 2003b).

The behaviour of $\mathrm{D}_{\mathrm{Fe}}$ as a function of $f \mathrm{O}_{2}$ can also be rationalized in terms of the LSM. At IW $\mathrm{D}_{\mathrm{Fe}}$ lies below the 2+ parabola (Figure 5a). With increasing $f \mathrm{O}_{2}, \mathrm{D}_{\mathrm{Fe}}$ increases (Figure 5b), lying close to the 2+ parabola at QFM (see also Figure 4), and significantly above the 3+ parabola in air (Figure 5b). The higher value of $\mathrm{D}_{\mathrm{Fe}}$ in air can be ascribed to incorporation of significant $\mathrm{Fe}^{3+}$ onto the tetrahedral site. The lower value of $\mathrm{D}_{\mathrm{Fe}}$ at $\mathrm{IW}$ is suggestive of the presence of some $\mathrm{Fe}_{0}$ in the melt (cf. Schreiber, 1986). The presence of $\mathrm{Fe}^{3+}$ on the T-site is supported by our preliminary SREF investigations (Aigner-Torres, 2003).

\section{Partitioning behaviour of Eu}

The LSM provides a quantitative framework for understanding the partitioning behaviour of Eu, which occurs as both $2+$ and $3+$ cations, depending on $f \mathrm{O}_{2}$. If all Eu is present as $\mathrm{Eu}^{3+} \mathrm{D}_{\mathrm{Eu}}$ will lie along the 3+ parabola defined by other, exclusively trivalent, REE (in-air run, Figure 5b). Conversely if all Eu is present as $\mathrm{Eu}^{2+}$, then $\mathrm{D}_{\mathrm{Eu}}$ will lie along the 2+ parabola defined by $\mathrm{Ca}, \mathrm{Sr}$, Ba etc (IW run, Figure 5b). The extent to which the real $\mathrm{D}_{\mathrm{Eu}}$ deviates from both parabolae contains information on the $\mathrm{Eu}^{2+} / \mathrm{Eu}^{3+}$ ratio in the melt, as previously noted by numerous workers. The virtue of the LSM approach, however, is that it can be used to constrain precisely $\mathrm{D}_{\mathrm{Eu}^{2+}}$ and $\mathrm{D}_{\mathrm{Eu} 3+}$ in a way not previously possible. Thus, most previous studies have been obliged to assume that $\mathrm{D}_{\mathrm{Eu} 2+}=\mathrm{D}_{\mathrm{Sr}}$, which is inconsistent with the slight difference in the ionic radii of these two cations (Shannon, 1976). 
Following Wilke \& Behrens (1999) it is a simple matter to show that:

$$
\left(\frac{\mathrm{Eu}^{2+}}{\mathrm{Eu}^{3+}}\right)_{m e l t}=\frac{D_{\mathrm{Eu}^{3+}}-D_{\mathrm{Eu}}}{D_{\mathrm{Eu}}-D_{\mathrm{Eu}^{2+}}}
$$

where $\mathrm{D}_{\mathrm{Eu} 3+}$ is the partition coefficient for $\mathrm{Eu}^{3+}, \mathrm{D}_{\mathrm{Eu} 2+}$ is the partition coefficient for $\mathrm{Eu}^{2+}$, and $\mathrm{D}_{\mathrm{Eu}}$ is the observed partition coefficient for mixed valence $\mathrm{Eu}$. $\mathrm{D}_{\mathrm{Eu} 3+}$ and $\mathrm{D}_{\mathrm{Eu} 2+}$ can be calculated using the LSM, based on the measured partition coefficient of another $\mathrm{REE}^{3+}$ and $\mathrm{Sr}$, respectively, using rearranged versions of Equation (1), Blundy \& Wood (1994):

$$
\begin{aligned}
& D_{E u^{2^{+}}}(P, T, X)=D_{S r}(P, T, X) \exp \left(\frac{-4 \pi E_{2+} N_{A}\left[\frac{r_{0(2+)}}{2}\left(r_{S r}^{2}-r_{E u^{2+}}^{2}\right)+\frac{1}{3}\left(r_{E u^{2+}}^{3}-r_{S r}^{3}\right)\right]}{R T}\right) \\
& D_{E u^{3+}}(P, T, X)=D_{R E E}(P, T, X) \exp \left(\frac{-4 \pi E_{3+} N_{A}\left[\frac{r_{0(3+)}}{2}\left(r_{R E E}^{2}-r_{E u^{3+}}^{2}\right)+\frac{1}{3}\left(r_{E u^{3+}}^{3}-r_{R E E}^{3}\right)\right]}{R T}\right)
\end{aligned}
$$

where $\mathrm{D}_{\mathrm{Sr}}(P, T, X)$ is the partition coefficient for $\mathrm{Sr}$ under the same pressure, temperature composition conditions, $\mathrm{D}_{\mathrm{REE}}(P, T, X)$ is the partition coefficient of another trivalent REE, ideally reasonably close in ionic radius to Eu ${ }^{3+}$, e.g. $\mathrm{Gd}$, Sm. Other parameters are defined as in Equation (1). Both $\mathrm{D}_{\mathrm{Sr}}$ and $\mathrm{D}_{\mathrm{REE}}$ can be measured directly, or calculated using expressions in Blundy \& Wood (1991) and Bindeman et al (1998). Ionic radii for $\mathrm{Eu}^{2+}, \mathrm{Eu}^{3+}, \mathrm{REE}^{3+}$ and $\mathrm{Sr}^{2+}$ in VIII-fold co-ordination are taken from Shannon (1976). The values of $\mathrm{r}_{0(2+)}, \mathrm{r}_{0(3+)}, \mathrm{E}_{(2+)}$ and $\mathrm{E}_{(3+)}$ can be taken from Blundy \& Wood (2003b) as follows:

$$
\begin{aligned}
& r_{0(2+)}(\AA)=1.258-0.057 X_{\mathrm{An}} \\
& r_{0(3+)}=r_{0(2+)}-0.03 \AA \\
& E_{2+}=116 \mathrm{GPa} \\
& E_{3+}=210 \mathrm{GPa}
\end{aligned}
$$

Note that these expressions effectively eliminate the influence of plagioclase crystal chemistry of Eu partitioning, by considering the effect of $\mathrm{X}_{\mathrm{An}}$ on site radius and Young's Modulus.

We have used equations (2-4) to calculate $\mathrm{Eu}^{2+} / \mathrm{Eu}^{3+}$ for our 9 plagioclase partitioning experiments in addition to 82 published experiments from the following sources: Sun et al. (1974), Drake (1975), Weill \& McKay (1975), McKay 
et al. (1994), Blundy (1997), Bindeman et al. (1998), Wilke \& Behrens (1999). In some of these studies (e.g. McKay et al., 1994, Blundy, 1997) the partition coefficients of both $\mathrm{Sr}$ and another REE, in addition to Eu and the anorthite content of the plagioclase, were reported, making application of equation (3) straightforward. For the other studies we have had to estimate some of the key parameters, namely: for Drake (1975), $\mathrm{D}_{\mathrm{Ce}}$ is taken from Drake \& Weill's (1975) experiments at similar P-T-X; for Wilke \& Behrens (1999) $\mathrm{D}_{\mathrm{Sr}}$ is estimated from Blundy \& Wood (1991) using reported An contents; for Sun et al (1974) $\mathrm{D}_{\mathrm{Eu}^{3}+}$ is estimated by extrapolating their linear equation (25) to high $\mathrm{fO}_{2}\left(10^{-3}\right)$ where almost all Eu is trivalent. $\mathrm{Eu}^{2+} / \mathrm{Eu}^{3+}$ can be easily converted to $\mathrm{Eu}^{3+} / \mathrm{Eu}_{\mathrm{tot}}$, the proportion of the total $\mathrm{Eu}$ in the melt that is trivalent, and this is plotted for all 91 experiments in Figure 6. The data describe a sigmoidal trend, as observed in all previous studies, with the cross-over from dominantly $\mathrm{Eu}^{3+}$ to dominantly $\mathrm{Eu}^{2+}$ between $f \mathrm{O}_{2}=10^{-10}$ and $10^{-13}$. In detail, although all datasets show similar sigmoidal patterns, there is scatter suggesting that parameters in addition to $\mathrm{fO}_{2}$ control $\mathrm{Eu}^{2+} / \mathrm{Eu}^{3+}$. These include temperature, pressure and melt composition. Given that all of the experiments were conducted at 1 atmosphere, with the exception of Wilke \& Behrens (1999), conducted at $500 \mathrm{MPa}$, we have insufficient data to investigate the effect of pressure. As the Wilke \& Behrens (1999) show no appreciable offset relative to the 1 atmosphere data, we suggest that the effect of pressure is negligible, consistent with the likely small difference in partial molar volume of $\mathrm{Eu}^{2+}$ and $\mathrm{Eu}^{3+}$ species in the melt. We will focus instead on temperature and melt compositional effects.

A useful parameter for exploring the role of temperature and melt composition of Eu redox equilibria is the standard redox potential, $E^{\prime}$, as defined by Schreiber (1986). $E^{\prime}$ is a measure of the reducibility of an ion pair relative to the equilibrium:

$$
\mathrm{O}_{2(\text { gas })}+4 e^{-}=2 \mathrm{O}_{\text {melt }}^{2-}
$$

$E^{\prime}$ can then be defined as:

$$
E^{\prime}=\frac{1}{4} \log _{10} f \mathrm{O}_{2}+\log _{10}\left(\frac{\mathrm{Eu}^{2+}}{\mathrm{Eu}^{3+}}\right)
$$

Thus, for any given melt composition, a plot of $\log _{10}\left(\mathrm{Eu}^{2+} / \mathrm{Eu}^{3+}\right)$ versus $\log _{10} f O_{2}$ will yield a slope of -0.25 and an intercept $E^{\prime}$. Such a plot is shown in Figure 7. The slope of -0.25 is clearly evident for all suites of data points. However, the intercept, i.e. $E^{\prime}$, varies from suite to suite, indicating that melt composition and/or temperature also play a role. In effect, this is the cause of the scatter apparent in Figure 6. We also note that for any given experimental suite, $E^{\prime}$ for experiments run in air is displaced to less negative values (Figure 7). Schreiber (1986) determined $E^{\prime}$ for a synthetic borosilicate melt $\left(57.9 \mathrm{wt} \% \mathrm{SiO}_{2}, 1.0 \% \mathrm{TiO}_{2}, 0.5 \% \mathrm{ZrO}_{2}, 14.7 \%\right.$ $\left.\mathrm{B}_{2} \mathrm{O}_{3} .0 .5 \% \mathrm{La}_{2} \mathrm{O}_{3}, 2.0 \% \mathrm{MgO}, 17.7 \% \mathrm{Na}_{2} \mathrm{O}, 5.7 \% \mathrm{Li}_{2} \mathrm{O}\right)$ at $1150^{\circ} \mathrm{C}$ to be -4.3 . This is significantly more negative than $E^{\prime}$ for any of the experiments we have considered (Figure 6) and consequently yields a sigmoidal pattern in that is displaced to lower $f \mathrm{O}_{2}$ from that shown by the Eu partitioning data. Morris et al. (1974) and Morris \& Haskin 
(1974) have also determined $\mathrm{Eu}^{2+} / \mathrm{Eu}^{3+}$ ratios for a range of synthetic melt compositions, more geologically realistic than that of Schreiber (1986), at temperatures of 1415 to $1650{ }^{\circ} \mathrm{C}$. Their values of $E^{\prime}$, calculated from equation (5), are in the range -1.3 to -3.3 and show a strong correlation with melt composition (Figure 8). If we exclude their $\mathrm{CaAl}_{2} \mathrm{Si}_{2} \mathrm{O}_{8}$ melts, which yield unusually low $E^{\prime}$ values, their mean value of $E^{\prime}$ is $-2.66 \pm 0.35$, which provides an excellent match to the plagioclase-melt Eu partitioning data, as shown in Figures 6 and 7. A global fit to the Eu partitioning data in Figure 7 yields $E^{\prime}$ is $-3.00 \pm 0.06\left(\mathrm{r}^{2}=0.45\right)$. Fits to specific datasets performed on a single bulk composition over a wide range of $f \mathrm{O}_{2}$ (Figure 7) yield slightly different values of $E^{\prime}$ with larger regression coefficients, e.g. Drake (1975), $-2.65 \pm 0.08\left(r^{2}=0.91\right)$; Sun et al. (1974), $-3.44 \pm 0.02\left(r^{2}=0.88\right)$; Wilke \& Behrens (1999), -3.36 \pm 0.08 ( $\left.\mathrm{r}^{2}=0.93\right)$; Weill \& McKay (1975), -2.64 $\pm 0.09\left(\mathrm{r}^{2}=0.90\right)$.

The uncertainty in the global-fit $E^{\prime}$ reflects variations between experiments, which may be thermal or compositional in origin. Morris and Haskin (1974) have shown that the thermal dependence of $E^{\prime}$ is very small, decreasing by only 0.2 units from $\sim 1400$ to $\sim 1600{ }^{\circ} \mathrm{C}$. Wilke \& Behrens (1999) arrive at a similar conclusion. We conclude that melt composition exercises a greater control over the observed scatter in $E^{\prime}$ than does temperature. Although a full parameterization of $E^{\prime}$ in terms of melt composition is beyond the scope of this study, and would probably require a much greater range of melt composition than is available in our dataset, it is instructive in understanding the persistent deviation of the in-air experimental data from the trends shown by experiments under more reducing conditions (Figure 7). We suggest that in air $\mathrm{Fe}$ in the melt is present almost exclusively as $\mathrm{Fe}^{3+}$, rather than $\mathrm{Fe}^{2+}$, which has a dramatic effect on melt structure and hence on $E^{\prime}$. The Morris and Haskin (1974) and Morris et al. (1974) data show that as the molar ratio of $\mathrm{Al}+\mathrm{Si} / \mathrm{O}$ in the melt increases (Figure 8), so $E^{\prime}$ becomes less negative. If we assume that $\mathrm{Fe}^{3+}$ has a similar structural role in the melt to $\mathrm{Al}^{3+}$ (e.g. Mysen et al., 1985), then the increase in $\mathrm{Fe}^{3+}$ under oxidizing conditions will have a similar effect to increasing $\mathrm{Al}+\mathrm{Si} / \mathrm{O}$ for any given melt composition, thereby making $E^{\prime}$ less negative. This is entirely consistent with the partitioning data in Figure 7.

We conclude that, although Eu partitioning data can be used to extract $E^{\prime}$ for natural melts, the strong melt compositional effects on $E^{\prime}$ need further clarification before Eu partition coefficients between plagioclase and melt can be used as a robust oxybarometer for silicate melts. The issue is compounded by the fact that in natural Febearing melts the influence of $\mathrm{Fe}^{3+}$ must also be accounted for, in a way that is not possible in the Fe-free experimental melts of Morris and Haskin (1974), Morris et al. (1974) and Schreiber (1986). Nonetheless, it is clear that once a suitable formalism for relating $E^{\prime}$ to melt chemistry is found, ideally through further experimental studies, plagioclase-melt partitioning can be used to quantify $f_{2}$ in magmatic rocks that lack other means of oxybarometry, such as coexisting Fe-Ti oxides.

\section{Petrogenetic implications for basaltic processes}

The wide range of data presented here for $\mathrm{D}$ values for plagioclase enable us to attempt to evaluate the conditions of formation of our natural sample ALV-3372. Since our experimental runs have investigated a small temperature range (Figure 3), we have averaged partition coefficients for each $f \mathrm{O}_{2}$ across all three isotherms $\left(1200 \pm 20^{\circ} \mathrm{C}\right)$. Average experimental D's are then compared with the averaged calculated partition coefficients for the plagioclase-matrix glass pair from ALV-3372 (Table 1) on a spider-diagram (Figure 9). For clarity, confidence intervals for averaged 
D's were calculated only under QFM conditions and are shown as error bars. Overall there is very good agreement between the experimental D's and those measured on the natural sample. Significantly, for all the elements that show multiple valence states, such as $\mathrm{Eu}, \mathrm{Cr}, \mathrm{Fe}$, and possibly Ti, the natural ALV-3372 D-values are intermediate between the averaged values for IW and QFM conditions.

An important feature of Figure 9 is the change in the ratio of D's - i.e., Kd values - between $\mathrm{Fe}$ and $\mathrm{Mg}$ under varying redox conditions. For example, at the IW buffer, $\mathrm{D}_{\mathrm{Fe}} / \mathrm{D}_{\mathrm{Mg}}$ is $0.8 \pm 0.4$, at $\mathrm{QFM}$ it is $2.6 \pm 0.4$, and in air it is 8.6 \pm 3.4 . The corresponding value for ALV-3372 is $1.40 \pm 0.37$, again suggestive of conditions between QFM and IW. The change in Fe-Mg fractionation cannot reflect temperature or plagioclase compositional variations, since both ranges are very small in our experiments. The ratio $\mathrm{D}_{\mathrm{Eu}} / \mathrm{D}_{\mathrm{Sr}}$ is also strongly sensitive to $f \mathrm{O}_{2}$, decreasing from $0.41 \pm 0.20$ at IW to $0.09 \pm 0.05$ at $\mathrm{QFM}$ and $0.09 \pm 0.01$ in air. The corresponding value for ALV-3372 is $0.13 \pm 0.04$. Based on a graphical comparison of the ALV-3372 data with the averaged experimental data for both $\mathrm{Kd} \mathrm{Fe}_{\mathrm{Mg}}$ and $\mathrm{Kd}_{\mathrm{Eu}-\mathrm{Sr}}$ we can constrain the $f \mathrm{O}_{2}$ of the natural sample to be 0.9 to $1.8 \mathrm{log}$ units below QFM (Figure 10), in excellent agreement with the estimates of Pacific MORB $f_{2}$ of Christie et al (1986) based on ferric-ferrous determinations of basaltic glasses, $1.6 \pm 0.5 \log$ units below QFM. The calculated $f \mathrm{O}_{2}$ for ALV-3372, using the modeling approach developed above, with an average $E^{\prime}$ of $3.24 \pm 0.12$ for our experiments at IW and QFM, yields $f \mathrm{O}_{2}$ between QFM-1.2 and QFM-0.7. Evidently the combined fractionation of $\mathrm{Eu}^{2+}-\mathrm{Sr}$ and $\mathrm{Fe}-\mathrm{Mg}$ by plagioclase has considerable potential as an oxybarometer for natural magmatic rocks.

\section{Conclusion}

The experimental partitioning of up to 34 different trace elements between plagioclase and basaltic melts under high temperature magmatic conditions and over a wide range of oxygen fugacity was accurately measured by laser ablation ICP-MS and their partition coefficients reported and compared with some previous studies. The combined effect of temperature and oxygen fugacity produce relative minor changes in most D values, with a general tendency of increasing $D$ with decreasing temperature, except for $\mathrm{D}_{\mathrm{Zr}}$. Partitioning data from divalent cations and REE on the large A-site of plagioclase are consistent with previous parameterizations using the lattice strain model. Overall, a wide range of new $\mathrm{D}$ values for several elements for plagioclase-bearing basaltic melts were determined and could be readily used for geochemical, modeling.

There is a significant change in plagioclase-melt partition coefficients for polyvalent elements $\mathrm{Fe}, \mathrm{Cr}$ and $\mathrm{Eu}$ with oxygen fugacity and consequently for Kd values of pairs of elements such as Fe-Mg and Eu-Sr. The best match of the experiments to natural sample ALV-3372 suggest that this magma equilibrated at conditions slightly more reducing than QFM.

Application of the lattice strain model to the partitioning of Eu provides a novel means of quantifying the $\mathrm{Eu}^{2+} / \mathrm{Eu}^{3+}$ ratio of the coexisting melt more precisely than was previously possible. By augmenting our dataset with published data on plagioclase-melt partitioning of Eu we have been able to show that $\mathrm{D}_{\mathrm{Eu}}$ is sensitive to both $f \mathrm{O} 2$ and melt composition. This variability requires parameterization before the potential of Eu partitioning between plagioclase and melt as an oxybarometer can be realized. The melt compositional sensitivity of $\mathrm{Eu}^{2+} / \mathrm{Eu}^{3+}$ ratios leads to a spread of $f \mathrm{O}_{2}$ values over which $\mathrm{D}_{\mathrm{Eu}}$ falls sharply due to the progressive oxidation of $\mathrm{Eu}^{2+}$ to $\mathrm{Eu}^{3+}$. The data show that for the 
melt compositions studied (basalt to tonalite), this change occurs at $f \mathrm{O}_{2}$ about $2 \log$ units more oxidizing than the IW buffer. At conditions more oxidizing than $\mathrm{QFM}+2$, the $\mathrm{Eu}^{2+} / \mathrm{Eu}^{3+}$ ratio sufficiently low (less than $10 \%$ total $\mathrm{Eu}$ as $\mathrm{Eu}^{2+} ;$ Figure 6) that plagioclase will not generate significant Eu anomalies in derivative melts.

\section{Acknowledgements}

M.A.-T. is indebted to the Swiss National Science Foundation for research grants and kindly thanks J. Sinton for providing the samples from the R/V Atlantis cruise 3-31. T. We thank T. Ntaflos from the University of Vienna for helping with the EMP analysis. JDB acknowledges a Senior Research Fellowship from the NERC.

This paper is dedicated to the memory of Prof. V. Trommsdorff.

\section{Figure Captions}

Fig. 1 Back-scattered electron image of run 25 showing analysis spots (laser ablation craters) in coexisting glass and plagioclase at quench temperature of $1180^{\circ} \mathrm{C}$ and QFM buffer conditions. Photo shows the entire experimental charge cross section.

Fig. $2 \mathrm{CaO} /\left(\mathrm{Na}_{2} \mathrm{O}+\mathrm{K}_{2} \mathrm{O}\right)$-ratios (wt.\%) of plagioclase versus coexisting liquids (quenched glasses) from this study (open and solid circles) compared with 1 bar experimental data from the literature (open diamonds) taken from Bender et al. (1978), Grove \& Bryan (1983), Tormey et al. (1987), Grove et al. (1990), Bartels et al. (1991), Baker et al. (1994), Yang et al. (1996), Thy et al. (1999), Sano et al. (2001). Open circles with arrows pointing to solid circle data points indicate run that have suffered $>15 \mathrm{wt} . \% \mathrm{Na}_{2} \mathrm{O}$-loss; arrow indicate the shift of the data points when the liquid (glass) analyses are corrected for $\mathrm{Na}_{2} \mathrm{O}$-loss occurring in long run duration experiments at low $\mathrm{fO}_{2}$ conditions (run \# 16, 17, and 35). The solid line indicates the $1: 1$ partitioning of $\mathrm{CaO} /\left(\mathrm{Na}_{2} \mathrm{O}+\mathrm{K}_{2} \mathrm{O}\right)$ between plagioclase and liquid and is only given for reference.

Fig. 3 Partition coefficients (log scale) of selected trace elements as a function of temperature for each oxygen fugacity studied. Also shown are the partition coefficients for natural sample ALV-3352-7 (Table 1).

Fig. 4 Onuma diagram for run $31\left(1200^{\circ} \mathrm{C} / \mathrm{QFM}\right)$ partition coefficients for $1+, 2+, 3+, 4+$ and $5+$ cations entering the plagioclase VIII-fold A-site and IV-fold T-site. Curves show nonlinear weighted least-square parabolic fits to Equation (1) for 1+, 2+ and 3+ cations entering the A-site. Eu and $\mathrm{Fe}$ are plotted for both 2+ and 3+ valence states. The position of these cations relative to the parabola suggests that both elements are dominantly $2+. \mathrm{Sc}, \mathrm{Cr}, \mathrm{Fe}^{3+}$, $\mathrm{Ti}$, $\mathrm{Zr}, \mathrm{Nb}$ and $\mathrm{Ta}$ are plotted as both IV and VIII co-ordination. The position of these cations relative to the A-site parabolae suggests that all occur preferentially on the T-site. 1 s.d. error bars are only shown if larger than symbol. Ionic radii from Shannon (1976), except $\mathrm{Nb}_{\mathrm{IV}}, \mathrm{Ta}_{\mathrm{IV}}, \mathrm{Sc}_{\mathrm{IV}}, \mathrm{Zr}_{\mathrm{IV}}$ and $\mathrm{Cr}_{\mathrm{IV}}$, which are extrapolated from higher coordination number radii. 
Fig. 5 Comparison of $D$ values for runs at $1220^{\circ} \mathrm{C}$ and three different oxygen fucacities. (a) $D$ 's for $2+$ and $3+$ cations from run 16 (IW buffer). Curves are fits to Lattice Strain Model (Equation (1), fit parameters in Table 6). Note that $\mathrm{D}_{\mathrm{Pb}}$ lies slightly above the 2+ parabola, while $\mathrm{D}_{\mathrm{Fe}}$ and $\mathrm{D}_{\mathrm{Mn}}$ lie slightly below. $\mathrm{D}_{\mathrm{Eu}}$ lies close to $\mathrm{D}_{\mathrm{Sr}}$ under these very reducing conditions, because of the predominance of $\mathrm{Eu}^{2+}$ over $\mathrm{Eu}^{3+}$. (b) Effect of $f \mathrm{O}_{2}$ on $\mathrm{D}_{\mathrm{Eu}}$ and $\mathrm{D}_{\mathrm{Fe}}$. The curves denote the $2+$ and $3+$ parabolae from (a) - the position of these curves is very similar in all three runs at 1220 ${ }^{\circ} \mathrm{C}$ as evinced by the near-constant $\mathrm{D}_{\mathrm{Sr}}$. The arrows show the effect of increasing $f \mathrm{O}_{2}$ from IW to air. $\mathrm{D}_{\mathrm{Eu}}$ is progressively displaced towards the $3+$ parabola as the $\mathrm{Eu}^{2+} / \mathrm{Eu}^{3+}$ ratio in the melt decreases. $\mathrm{D}_{\mathrm{Fe}}$ shows the opposite behaviour. At QFM $\mathrm{D}_{\mathrm{Fe}}$ lies close to the 2+ parabola, suggesting that this is the dominant species in the melt. In air $\mathrm{D}_{\mathrm{Fe}}$ is displaced above the 2+ parabola, due to incorporation of significant $\mathrm{Fe}^{3+}$ onto the T-site. The displacement of $\mathrm{D}_{\mathrm{Fe}}$ to lower values in the IW experiment may reflect the presence of significant $\mathrm{Fe}_{0}$ in the melt under such reducing conditions (cf. Schreiber, 1986). 1 s.d. error bars as in Figure 4. Ionic radii from Shannon (1976).

Fig. 6 Variation in $\mathrm{Eu}^{3+} / \mathrm{Eu}_{\mathrm{tot}}$ ratio as a function of $f \mathrm{O}_{2}$ in melts coexisting with plagioclase for various experimental studies calculated according to equations (2) to (4). Data sources are: SWS74, Sun et al. (1974); D75, Drake (1975); WM75, Weill \& McKay (1975); MLWC94, McKay et al. (1994); B97, Blundy (1997); BDD98, Bindeman et al. (1998); WB99, Wilke \& Behrens (1999); and this study. The curved lines denote calculated variation in $\mathrm{Eu}^{3+} / \mathrm{Eu}_{\text {tot }}$ labeled for different values of the reduction potential, $E^{\prime}$, as defined in Equation (5). The curve labeled S86 denotes the curve for $E^{\prime}=-4.3$ as determined for a synthetic melt by Schreiber (1986). The experimental data for geologically realistic melts are best described with $E^{\prime}$ in the range -3.5 to -2.5 . Note that for melt more oxidizing than QFM+2 $\left(f \mathrm{O}_{2} \sim 10^{-6}\right)$ over $90 \%$ of $\mathrm{Eu}$ is trivalent.

Fig. 7 Variation in $\log _{10}\left(\mathrm{Eu}^{2+} / \mathrm{Eu}^{3+}\right)$ as a function of $\log _{10} f \mathrm{O}_{2}$ for the same experimental data as Figure 6. Straight lines denote different values of $E^{\prime}$, as defined in Equation (5), fitted to individual datasets (straight lines). Note how in-air data for any given bulk composition are displaced to less negative values of $E^{\prime}$, due to melt structure changes resulting from oxidation of $\mathrm{Fe}^{2+}$ to $\mathrm{Fe}^{3+}$.

Fig. 8 Dependence of $E^{\prime}$ on melt composition, as expressed in terms of molar $(\mathrm{Al}+\mathrm{Si}) / \mathrm{O}$, from isothermal experiments of Morris \& Haskin (1974) and polythermal experiments Morris et al. (1974). For an Fe-bearing melt oxidation of $\mathrm{Fe}^{2+}$ to $\mathrm{Fe}^{3+}$ is likely to have a similar structural effect on the melt as increasing $(\mathrm{Al}+\mathrm{Si}) / \mathrm{O}$ and so making $E^{\prime}$ less negative as observed in Figure 7. The horizontal lines denote the range of $E^{\prime}$ from Figs. 6 and 7.

Fig. 9 Comparison of average experimental partition coefficients under different $f \mathrm{O} 2$ conditions (Table 5) with natural plagioclase-matrix data from sample ALV-3352-7 (Table 1) plotted on an extended spider diagram. Confidence intervals $(\mathrm{p}=0.95)$ only shown as error bars for $\mathrm{QFM}$ average. Not the strong $f \mathrm{O}_{2}$-sensitive fractionation of Fe from $\mathrm{Mg}$. 
Fig. 10 Graphical estimation of $f \mathrm{O}_{2}$ for natural sample ALV-3352-7 based on $\mathrm{Kd}_{\mathrm{Fe}-\mathrm{Mg}}$ and $\mathrm{Kd}_{\mathrm{Eu}-\mathrm{Sr}}$. The average experimental data $\left(1180-1220^{\circ} \mathrm{C}\right)$ with 1 s.d. error bars are plotted as a function of $f \mathrm{O}_{2}$ relative to $\mathrm{QFM}$ and connected with straight lines. The corresponding values for the plagioclase-matrix pair from ALV-3352-7 are interpolated between the QFM and IW data points to estimate $f \mathrm{O}_{2}$.

\section{Table captions}

Table 1 Composition of bulk starting material, plagioclase and matrix glass and comparison of different analytical techniques.

Table 2 Selected experimental conditions and run products

Table 3 Electron microprobe (wt\%) analyses of run products

Table 4 Laser Ablation ICP-MS (ppm) analysis of run products

Table 5 Average plagioclase-melt partition coefficients

Table 6 Fit parameters to the Lattice Strain Model (Equation 1) for 2+ and 3+ cations in selected runs.

\section{References}

Aigner-Torres, M. (2003). Iron, magnesium and other highly incompatible elements partitioning between plagioclase and basaltic melts: an experimental and analytical approach. Ph.D. thesis Nr. 15026, ETH Zurich.

Baker MB, Grove TL, Price R (1994). Primitive basalts and andesites from the Mt. Shasta region, N. California: products of varying melt fraction and water content. Contrib. Mineral. Petrol. 118:111-129.

Bartels KS, Kinzler RJ, Grove TL (1991). High pressure phase relations of primitive high-alumina basalts from Medicine Lake volcano, northern California. Contrib. Mineral. Petrol. 108:253-270.

Bender A, Hodges FN, Bence AE (1978). Petrogenesis of basalts from the Project FAMOUS area. Earth Planet. Sci. Lett. 41:277-302.

Bindeman, I. and A. Davis (2000). Trace element partitioning between plagioclase and melt: Investigation of dopant influence on partition behavior. Geochimica et Cosmochimica Acta 64 (16), 2863-2878.

Bindeman, I., A. Davis, and M. Drake (1998). Ion microprobe study of plagioclase-basalt partition experiments at natural concentration levels of trace elements. Geochimica et Cosmochimica Acta 62 (7), 1175-1193.

Blundy, J. (1997). Experimental study of a Kiglapait marginal rock and implications for trace element partitioning in layered intrusions. Chemical Geology 141, 73-92.

Blundy, J. and B. Wood (1991). Crystal-chemical controls on the partitioning of $\mathrm{Sr}$ and Ba between plagioclase feldspar, silicate melts, and hydrothermal solutions. Geochimica et Cosmochimica Acta 55, 193-209. 
Blundy, J. and B. Wood (1994). Prediction of crystal-melt partition coefficients from elastic moduli. Nature 372, 452-454.

Blundy, J. and B. Wood (2003a). Partitioning of trace elements between crystals and melts. Earth and Planetary Science Letters 210, 383-397.

Blundy, J., and B. Wood, (2003b). Mineral-melt partitioning of uranium, thorium and their daughters. In: Uraniumseries geochemistry (B. Bourdon et al., eds.) Reviews in Mineralogy, 52, 39-123.

Borisov, A. and J. Jones (1999). An evaluations of Re, as an alternative to Pt, for the 1 bar loop technique: An experimental study at $1400^{\circ} \mathrm{C}$. Am. Mineral. $84,1528-1534$.

Brice, J. (1975). Some thermodynamics aspects of the growth of strained crystals. J. Cryst. Growth 28, 249-253.

Bryan, W. (1974). Fe-Mg relationships in sector-zoned submarine basalt plagioclase. Earth and Planetary Science Letters 24, 157-165.

Christie, D., I. Carmichael, and C. Langmuir (1986). Oxidation states of mid-ocean ridge basalt glasses. Earth Planet. Sci. Lett. 79, 397-411.

Drake, M.J. (1975). The oxidation state of europium as an indicator of oxygen fugacity. Geochim Cosmochim Acta 39, 55-64.

Drake, M.J. and D.F. Weill (1975). Partition of Sr, Ba, $\mathrm{Eu}^{2+}, \mathrm{Eu}^{3+}$ and other REE between plagioclase feldspar and magmatic liquid: an experimental study, Geochim Cosmochim Acta 39, 689-712.

Grove, T. (1981). Use of FePt alloy to eliminate the iron loss problem in 1 atmosphere gas mixing experiments: Theoretical and practical considerations. Contrib. Mineral. Petrol. 78, 298-304.

Grove, T., M. Baker, and R. Kinzler (1984). Coupled CaAl-NaSi diffusion in plagioclase feldspar: Experiments and application to cooling rate speedometry. Geochim. Cosmochim. Acta 48, 2113-2121.

Grove TL, Baker MB, Kinzler RJ (1984) Coupled CaAl-NaSi diffusion in plagioclase feldspar: Experiments and applications to cooling rate speedometry. Geochim. Cosmochim. Acta 48:2113-2121

Grove TL, Bryan WB (1983) Fractionation of pyx-phyric MORB at low pressure. An experimental study. Contrib. Mineral. Petrol. 84:293-309

Grove TL, Kinzler RJ, Bryan WB (1990) Natural and experimental phase relations of lavas from Serocki Volcano. In: Detrick R, Honnorez J, Bryan WB, et al. (eds) Proceeding of the Ocean Drilling Program, Scientific Results, vol 106. Ocean Drilling Program, College Statiom;TX, pp 9-17

Günther, D., R. Frischknecht, C. Heinrich, and H. Kahlert (1997). Capabilities of an argon fluoride $193 \mathrm{~nm}$ excimer laser for laser ablation inductively coupled plasma mass spectrometry microanalysis of geological materials. Journal of Analytical Atomic Spectrometry 12 (9), 939-944.

Heinrich, C., T. Pettke, W. Halter, M. Aigner-Torres, A. Audètat, D. Günther, B. Hattendorf, D. Bleiner, M. Guillong, and I. Horn (2003). Quantitative multi-element analysis of minerals, fluid and melt inclusions by laserablation inductively-coupled-plasma mass- spectrometry. Geochimica et Cosmochimica Acta 67, 3473-3496.

Hofmeister, A. and G. Rossman (1984). Determination of $\mathrm{Fe}^{3+}$ and $\mathrm{Fe}^{2+}$ concentrations in feldspar by optical absorption and EPR spectroscopy. Phys. Chem. Minerals. 11, 213-224. 
Longerich, H., S. Jackson, and D. Guenther (1996). Laser ablation inductively coupled plasma mass spectrometric transient signal data acquisition and analyte concentration calculation. Journal of Analytical Atomic Spectrometry 11, 899-904.

Longhi, J., D. Walker, and J. Hays (1976). Fe and Mg in plagioclase. Proc. Lunar Sci. Conf. 7th, 1281-1300.

McKay, G., L. Le, J. Wagstaff, and G. Crozaz (1994). Experimental partitioning of rare earth elements and strontium: constraints on petrogenesis and redox conditions during crystallization of Antarctic angrite Lewis Cliff 86010. Geochim Cosmochim Acta 58, 2911-2919.

Meyer, P. and T. Shibata (1990). Complex zoning in plagioclase feldspars from ODP site 648. In R. Detrick, J. Honnorez, W. Bryan, and T. Juteau (Eds.), Proc. ODP, Sci. Results, Volume 106/109, pp. 123-142.

Morris, R.V. and L.A. Haskin (1974). EPR measurement of the effect of glass composition on the oxidation data of europium. Geochim Cosmochim Acta, 38, 1435-1446.

Morris, R.V., L.A. Haskin, G.M. Biggar and M.J. O’Hara (1974) Measurement of the effects of temperature and partial pressure of oxygen on the oxidation states of europium in silicate glasses. Geochim Cosmochim Acta, 38, 1447-1459.

Morse, S. (1984). Cation diffusion in plagioclase feldspar. Science 225, 504-505.

Murakami, H., M. Kimata, S. Shimoda, E. Ito, and S. Sasaki (1992). Solubility of $\mathrm{CaMgSi}_{3} \mathrm{O}_{8}$ and $\mathrm{Si}_{4} \mathrm{O}_{8}$ endmembers in anorthite. J Mineral Pet Econ Geol 87, 491-509.

Mysen, B.O., D. Virgo, E., Neumann and F., Seifert (1985). Redox equilibria and the structural states of ferric and ferrous iron in melts in the system $\mathrm{CaO}-\mathrm{MgO}-\mathrm{Al}_{2} \mathrm{O}_{3}-\mathrm{SiO}_{2}-\mathrm{Fe}-\mathrm{O}$ : relationships between redox equilibria, melt structure and liquidus phase equilibria American Mineralogist, 70, 317-331.

Onuma, N., H. Higuchi, H. Wakita, and H. Nagasawa (1968). Trace element partition between two pyroxenes and the host lava. Earth Planet. Sci. Lett. 5, 47-51.

Peters, M., E. Shaffer, and D. Burnett (1994). Mg and Ti partition coefficients for anorthite-CAI liquid: dependence on oxygen fugacity and melt composition. Lunar Planet. Sci. XXV, 1075-1076.

Peters, M., Shaffer, E., Burnett, D. and Kim, S. (1995). Magnesium and titanium partitioning between anorthite and type B CAI liquid: dependence on oxygen fugacity and liquid composition. Geochim. Cosmochim. Acta 59 (13), 2785-2796.

Pettke, T. (2006). In situ laser-ablation ICPMS analysis of melt inclusions and prospects for constraining subduction zone magmatism. Mineralogical Association of Canada, Montreal, Quebec 36, 51-80.

Pettke, T., W. E. Halter, J. D. Webster, M. Aigner-Torres, and C. A. Heinrich (2004). Accurate quantification of melt inclusion chemistry by LAICPMS: a comparison with EMP and SIMS and advantages and possible limitations of these methods. Lithos 78, 333-361.

Pettke, T., C. Heinrich, A. Ciocan, and D. Günther (2000). Quadrupole mass spectrometry and optical emission spectroscopy: detection capabilities and representative sampling of short transient signals from laser ablation. Journal of Analytical Atomic Spectrometry 15, 1149-1155.

Phinney, W. (1992). Partition coefficients for iron between plagioclase and basalt as a function of oxygen fugacity: Implications for archean and lunar anorthosites. Geochimica et Cosmochimica Acta 56, 1885-1895. 
Phinney, W. (1994). FeO and MgO in plagioclase of lunar anorthosites: igneous or metamorphic? Lunar Planet. Sci. XXV, 1081-1082.

Sano T, Fujii T, Deshmukh SS, Fukuoka T, Aramaki S (2001) Differentiation processes of Deccan Trap basalts: Contribution from geochemistry and experimental petrology. J. Petrol. 42:2175-2195.

Sato, H. (1989). Mg-Fe partitioning between plagioclase and liquid in basalts of hole 504B, ODP Leg 111: a study of melting at 1 atm. In K. Becker, H. Sakai, et al. (Eds.), Proceeding of the Ocean Drilling Project, Scientific Results, Volume 111, pp. 17-26.

Schreiber, H.D. (1986). Redox processes in glass-forming melts. Journal of Non-Crystalline Solids 84, 129-141

Schümann, K. and S. Hafner (1972). On the amount of ferric iron in plagioclases from lunar igneous rocks. Geochimica et Cosmochimica Acta 1, 615-621.

Sclar, C. and A. Benimoff (1980). Magnesium in anorthite: synthesis and petrological significance of the $\mathrm{CaMgSi}_{3} \mathrm{O}_{8}$ series. EOS Am Geophys Union 61, 392.

Sclar, C. and R. Kastelic (1979). Iron in anorthite: synthesis and characterization of the $\mathrm{CaAl}_{2} \mathrm{Si}_{2} \mathrm{O}_{8}-\mathrm{CaFeSi}_{3} \mathrm{O}_{8}$ series. EOS Am Geophys Union 60, 421.

Shannon, B. (1976). Revised effective ionic radii and systematic studies of interatomic distances in halides and chalcogenides. Acta Crystallogr. 32 A, 751-767.

Simon, S., S. Kuehner, A. Davis, L. Grossman, M. Johnson, and D. Burnett (1994). Experimental studies of trace element partitioning in $\mathrm{Ca}, \mathrm{Al}$-rich compositions: anorthite and perowskite. Geochim. Cosmochim. Acta 58 (5), $1507-1523$.

Sinton, J., E. Bergmanis, R. Batiza, K. Rubin, T. Gregg, K. Grønvold, S. White, K. Macdonald, C. Van Dover, M. Cormier, W. Ryan, M. Aigner- Torres, L. Popels, E. Boyle, A. Shah, and W. Jin (1999). Volcanological investigations at superfast spreading: results from R/V Atlantis cruise 3-31. Ridge Events 10 (1), 17-23.

Smith, J. and W. Brown (1988). Feldspar Minerals (2 ed.), Volume 1. Springer-Verlag.

Sun, C., Williams, R. J. and Sun, S. S., 1974. Distribution coefficients of Eu and Sr for plagioclase-liquid and clinopyroxene-liquid in oceanic ridge basalt: an experimental study. Geochim. Cosmochim. Acta., 38, 1415-1433.

Thy P, Lesher CE, Mayfield JD (1999) Low-pressure melting studies and basalt and basaltic andesite fro the southeast Greenland continetal margin and the origin of dacites at site 917. In: H.C. L, Duncan AR, Allan JF, Brooks L, et al. (eds) Proceedings of the Ocean Drilling Program, Scientific Results, vol 163. Ocean Drilling Program, College Station, TX, pp 95-112.

Tormey, D., T. Grove, and W. Bryan (1987). Experimental petrology of normal MORB near the Kane Fracture Zone: $22^{\circ}-25^{\circ} \mathrm{N}$, mid-Atlantic ridge. Contrib. Mineral. Petrol. 1987, 121-139.

Tormey DR, Grove TL, Bryan WB (1987) Experimental petrology of normal MORB near the Kane fracture zone: 22 - 25N, mid-Atlantic ridge. Contrib. Mineral. Petrol. 96:121-139.

Urusov, V. and V. Dudnikova (1998). The trace-component trapping effect: experimental evidence, theoretical interpretation, and geochemical applications. Geochimica et Cosmochimica Acta 62, 1233-1240.

Weill, D.F. and G.A. McKay (1975). The partitioning of Mg, Fe, Sr, Ce, Sm, Eu and $\mathrm{Yb}$ in lunar igneous systems and a possible origin of KREEP by equilibrium partial melting. Proc Lunar Sci Conf $6^{\text {th }}, 1143-1158$. 
Wenk, H. R. and W. R. Wilde (1973). Chemical anomalies of lunar plagioclase, described by substitution vectors and their relation to optical and structural properties. Contributions to Mineralogy and Petrology 41 (2), 89-104.

Wenk, H. R., W. R. Wilde, and W. F. Mueller (1973). Lunar plagioclase; a study of feldspar chemistry and its relation to optical and structural properties. In Lunar Science IV, Abstracts, pp. 781-783. Inst., Houston, Texas: Lunar Sci.

Wilke, M. and H. Behrens (1999). The dependence of the partitioning of iron and europium between plagioclase and hydrous tonalitic melt on oxygen fugacity. Contributions to Mineralogy and Petrology 137, 102-114.

Yang H-J, Kinzler RJ, Grove TL (1996) Experiments and models of anhydrous basaltic olivine-plagioclase-augite saturated melts from 0.001 to 10 kbar. Contrib. Mineral. Petrol. 124, pages?

Zeng, R. (1985). $\mathrm{CaMgSi}_{3} \mathrm{O}_{8}$, the MacKenzie's molecule, a possible indicator of supercooling. Bulletin of Volcanology 108, 713-718. 


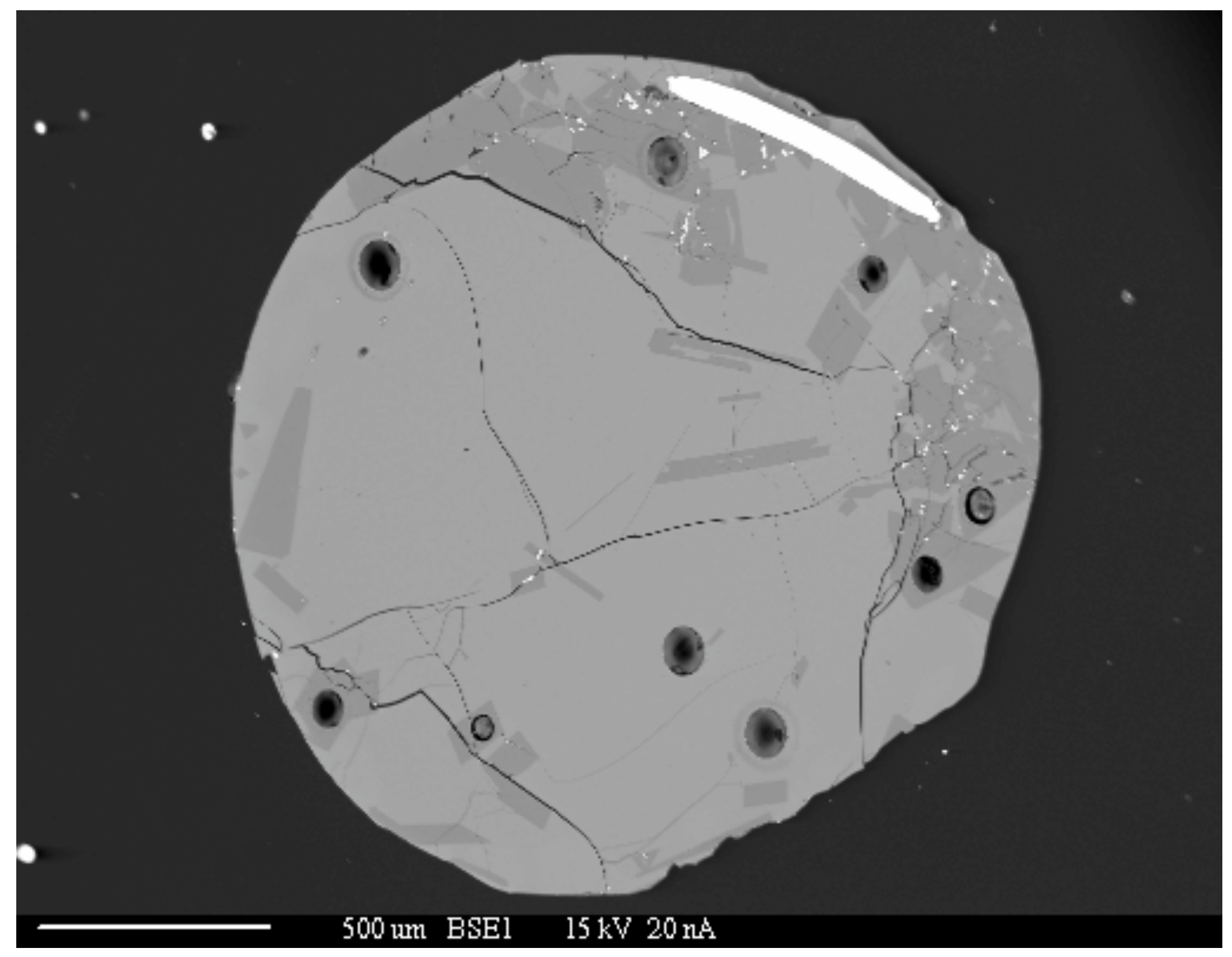




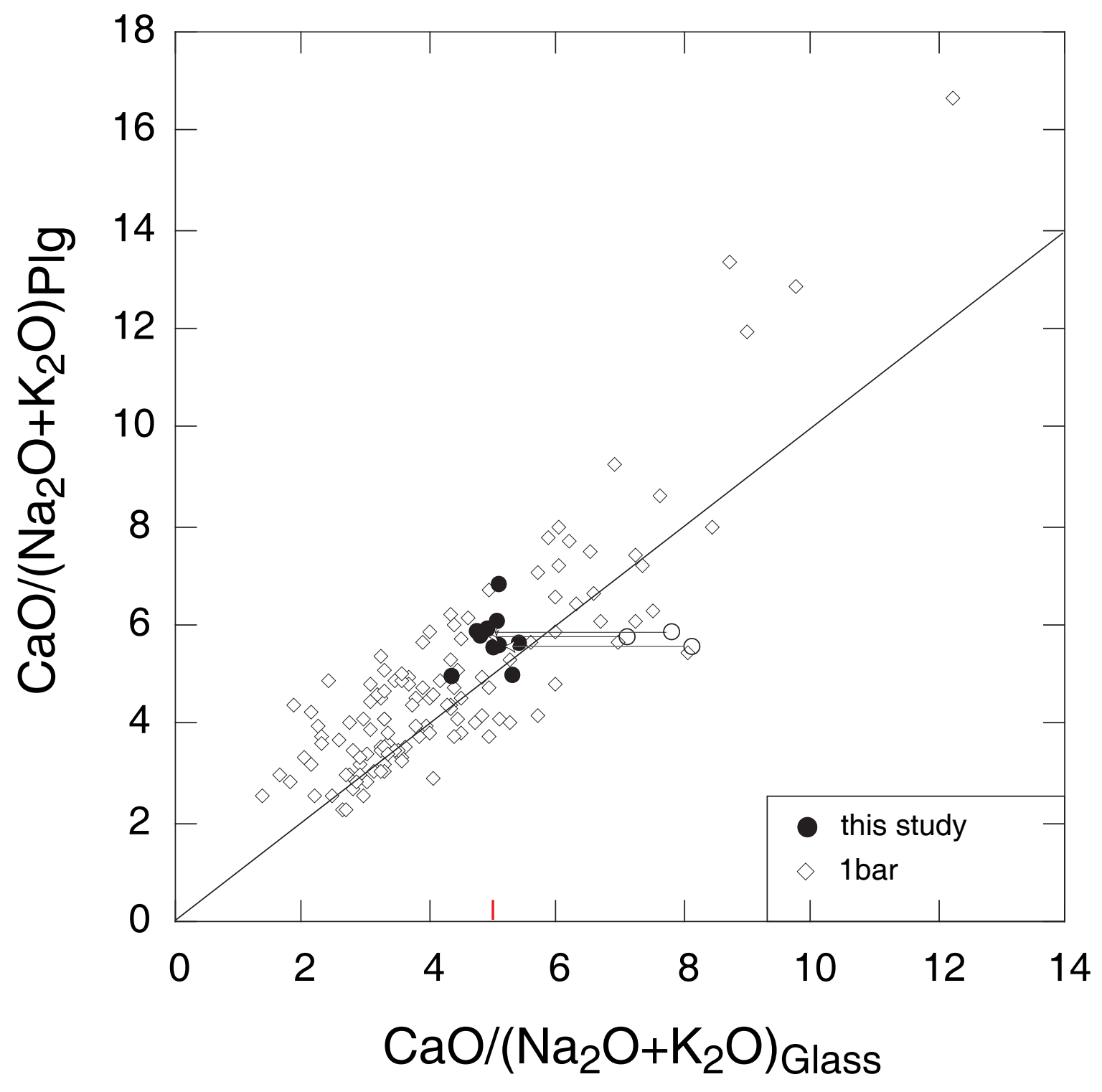




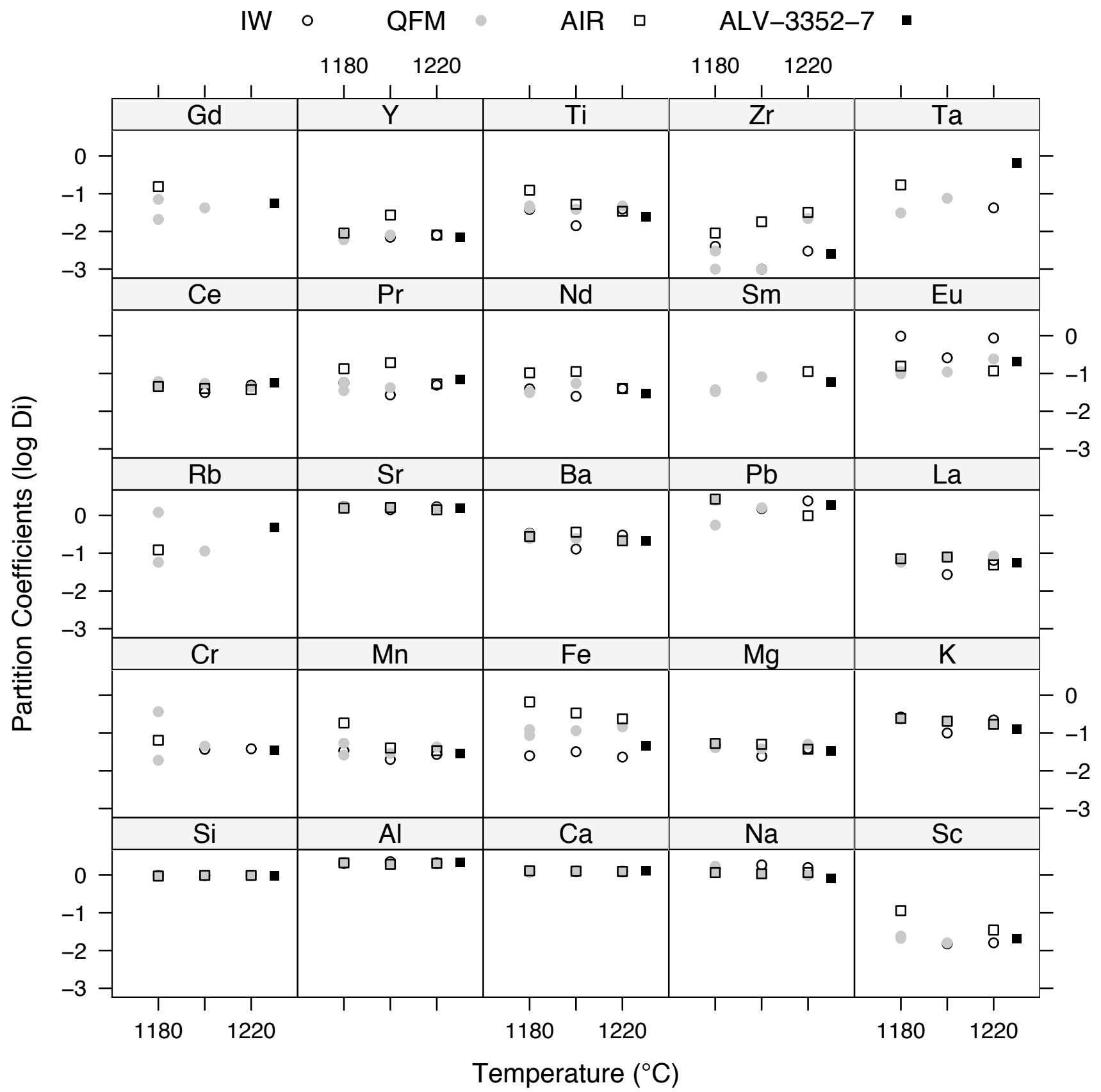




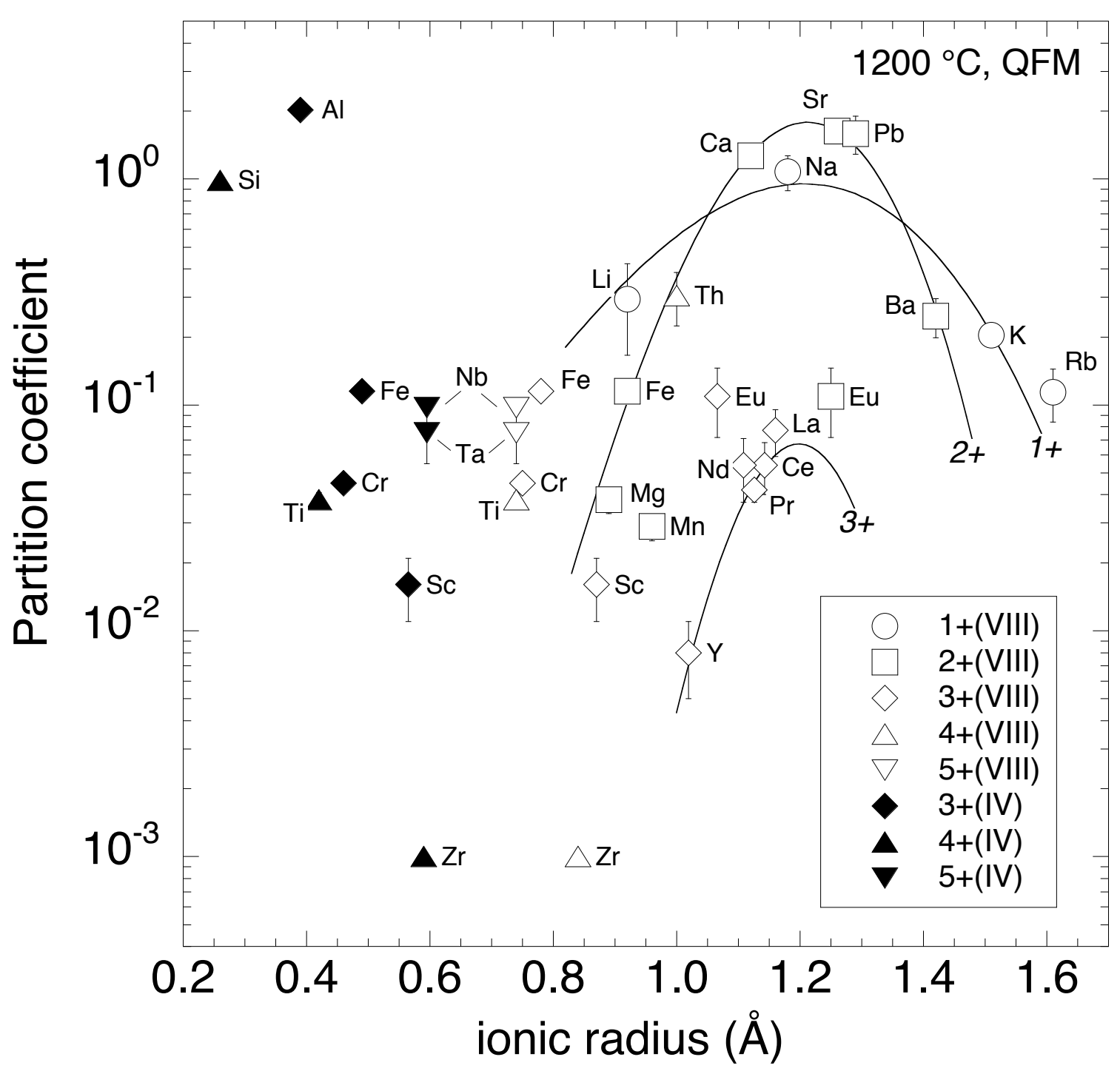




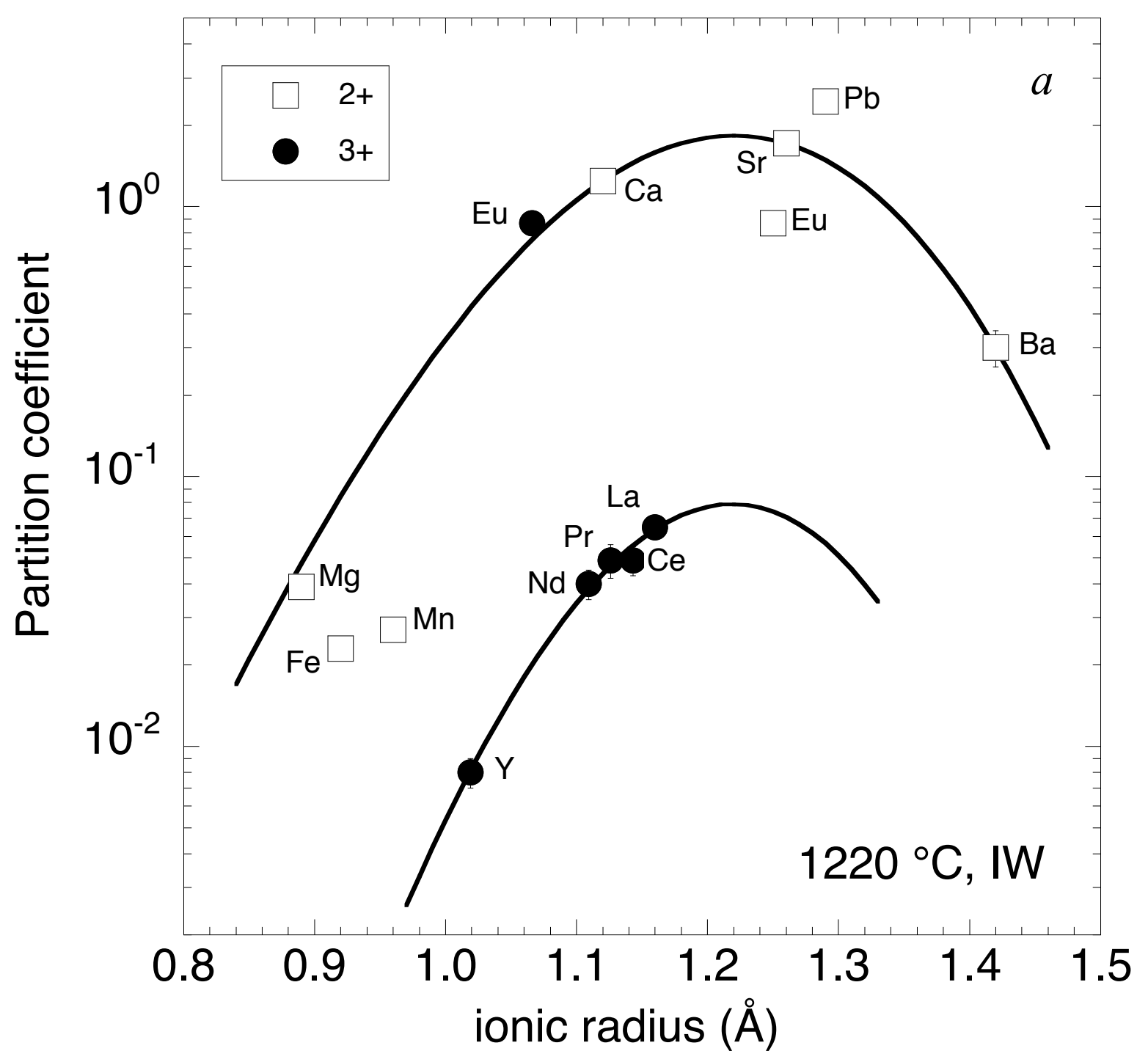




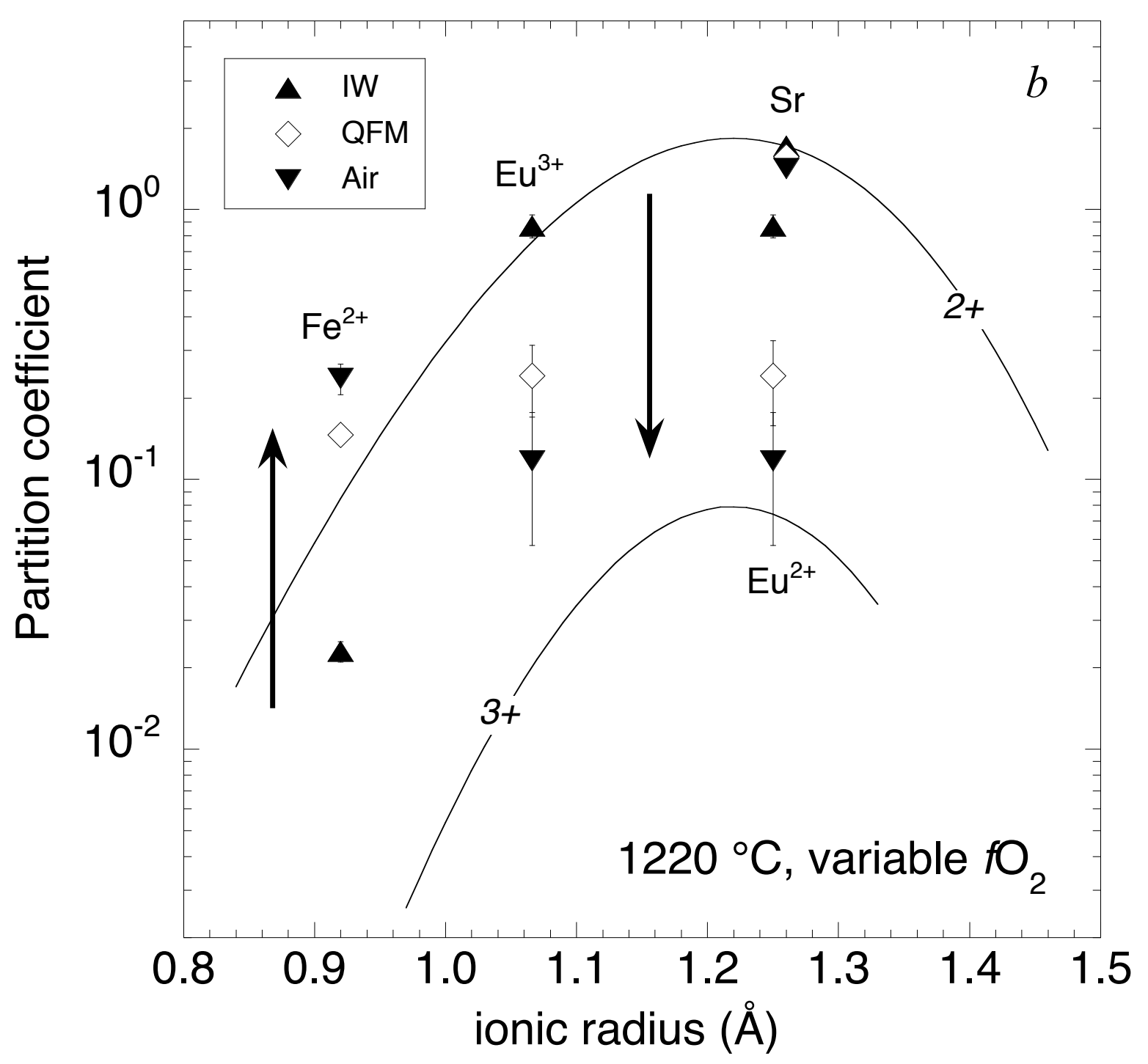




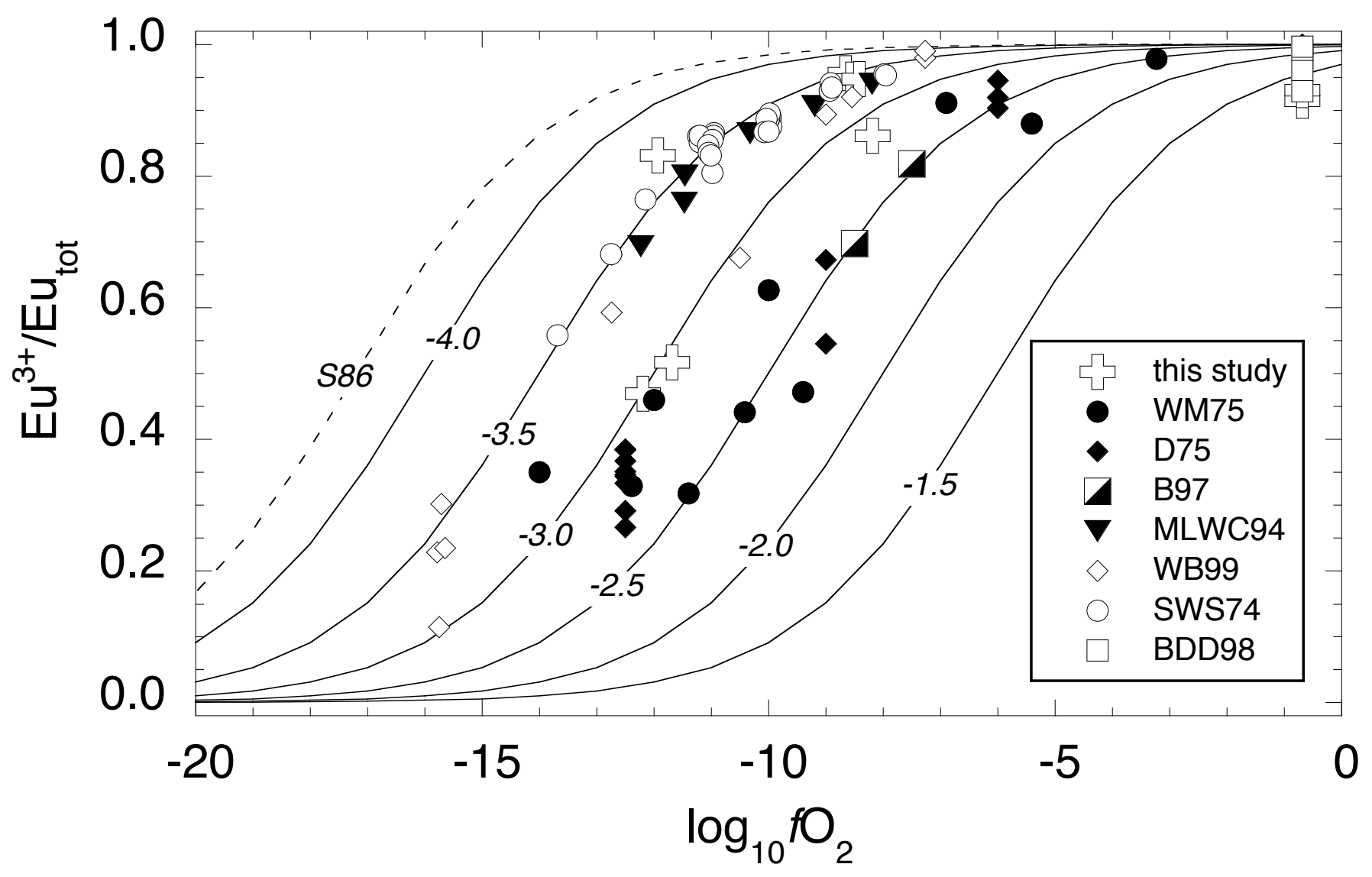




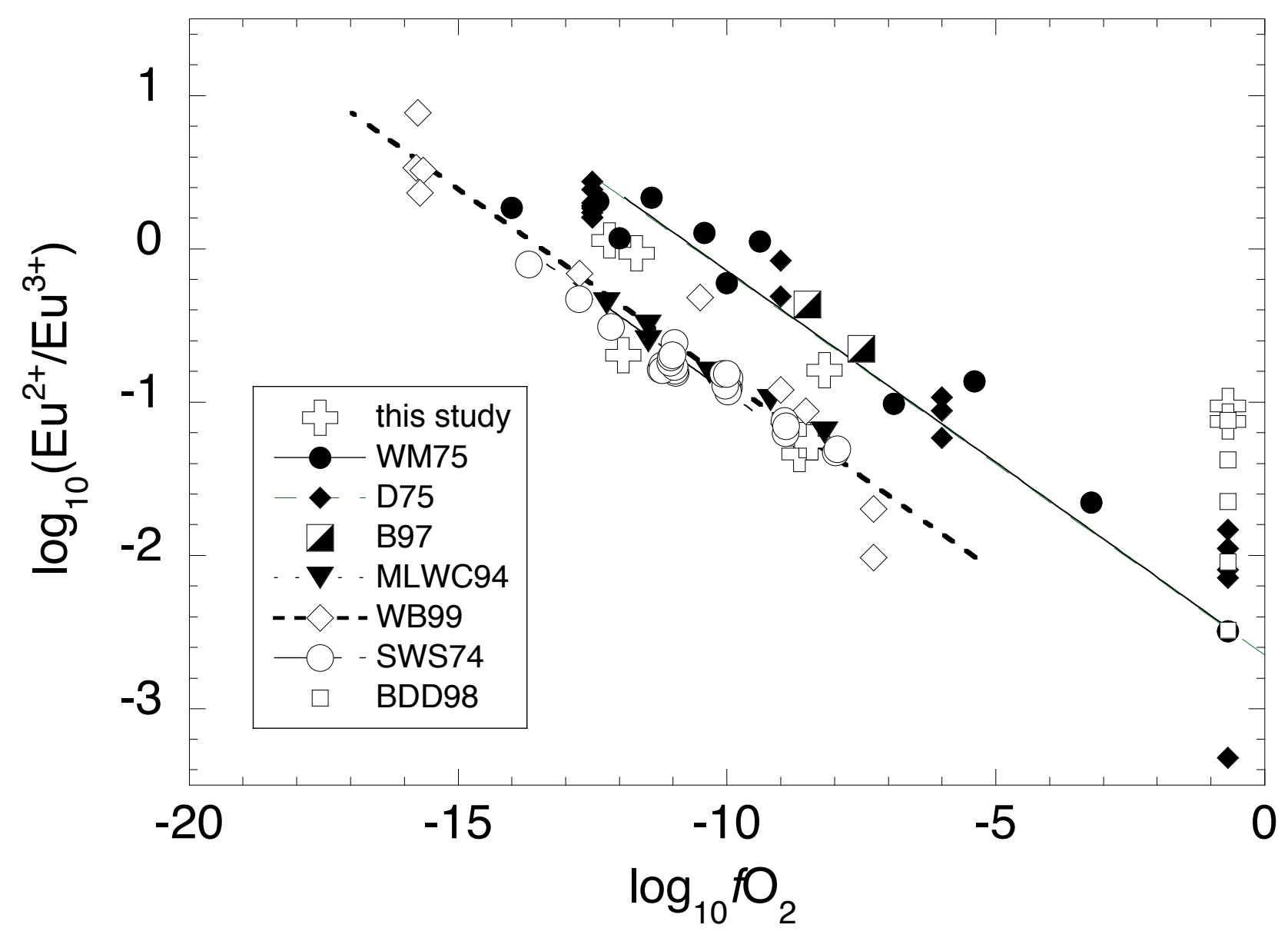




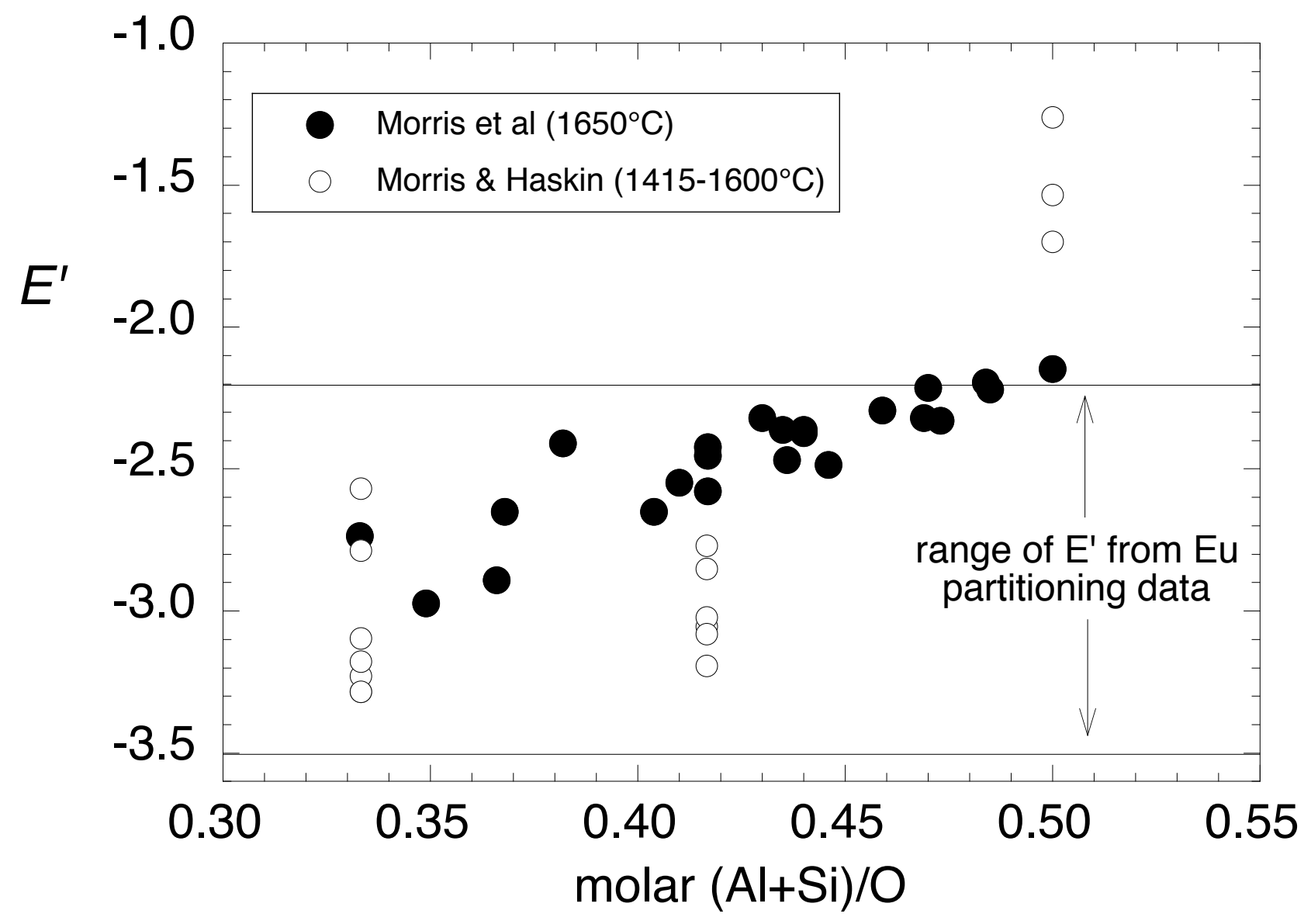




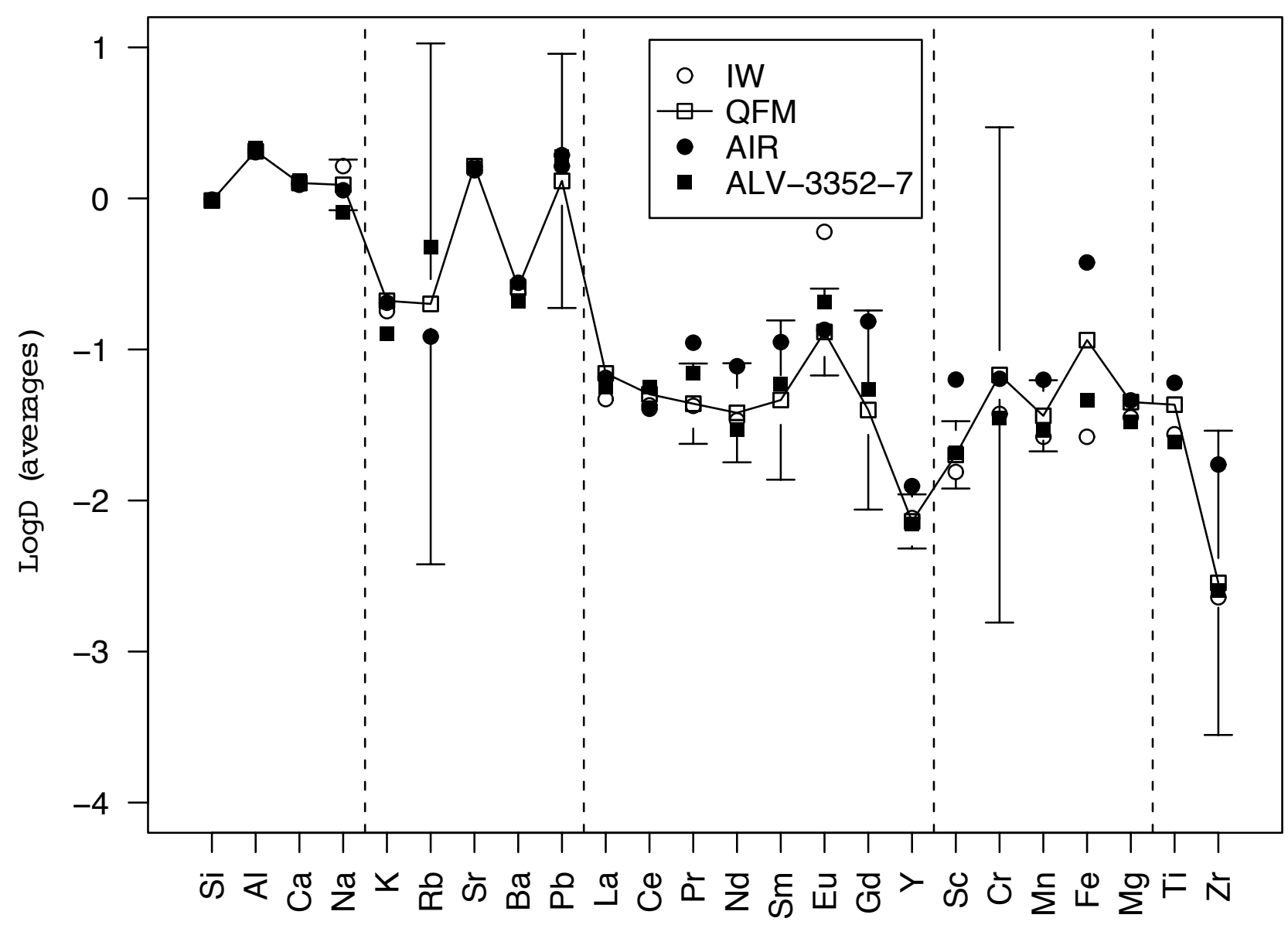




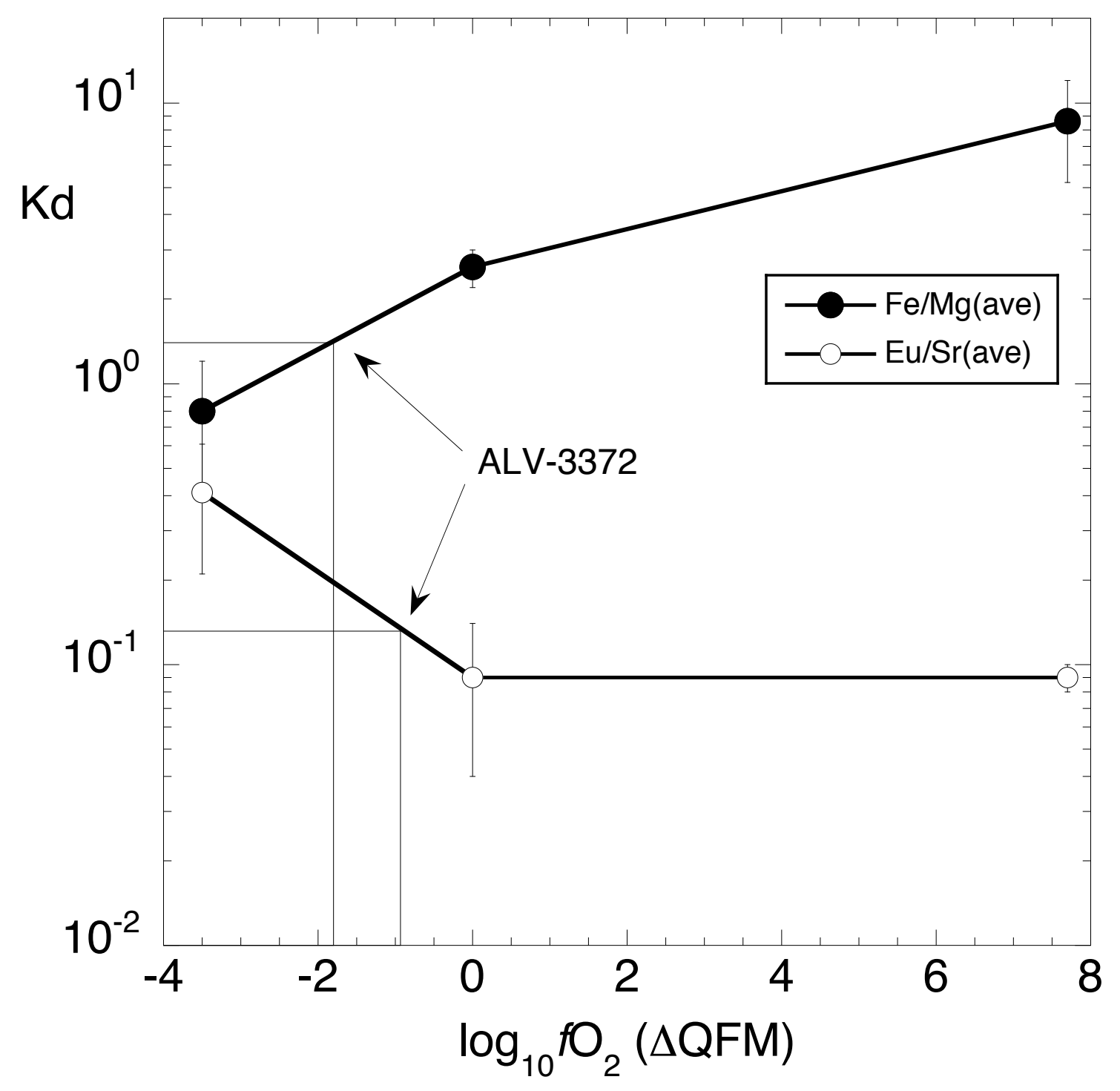


Table 1: Composition of starting material and method comparisons

\begin{tabular}{|c|c|c|c|c|c|c|c|c|c|c|c|c|c|}
\hline \multirow[b]{3}{*}{$n^{c}$} & \multirow{3}{*}{$\begin{array}{c}\text { Bulk rock }{ }^{\mathrm{a}} \\
\text { XRF }\end{array}$} & \multicolumn{4}{|c|}{ run no. $23^{\mathrm{b}}$} & \multicolumn{4}{|c|}{ Plagioclase $^{c}$} & \multicolumn{4}{|c|}{ Matrix Glass ${ }^{c}$} \\
\hline & & \multicolumn{2}{|c|}{ EMPA $^{a}$} & \multicolumn{2}{|c|}{ LA-ICP-MS $^{a}$} & \multicolumn{2}{|c|}{ EMPA } & \multicolumn{2}{|c|}{ LA-ICP-MS } & \multicolumn{2}{|c|}{ EMPA } & \multicolumn{2}{|c|}{ LA-ICPMS } \\
\hline & & 6 & 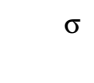 & 4 & $\sigma$ & 50 & $\sigma$ & 17 & $\sigma$ & 20 & $\sigma$ & 20 & $\sigma$ \\
\hline $\mathrm{SiO} 2$ & 50.4 & 49.5 & 0.4 & 50.8 & 0.17 & 48.0 & 1.4 & 48.9 & 6.1 & 50.2 & 0.1 & 51.2 & 4.2 \\
\hline TiO2 & 1.31 & 1.24 & 0.06 & 1.07 & 0.005 & 0.039 & 0.014 & 0.028 & 0.007 & 1.33 & 0.05 & 1.15 & 0.03 \\
\hline $\mathrm{Al} 2 \mathrm{O} 3$ & 15.53 & 15.98 & 0.08 & 16.99 & 0.05 & 32.5 & 0.9 & 32.67 & 3.3 & 15.2 & 0.1 & 15.7 & 1.2 \\
\hline $\mathrm{FeO}$ & 9.48 & 8.36 & 0.12 & 8.50 & 0.09 & 0.427 & 0.075 & 0.413 & 0.053 & 9.14 & 0.10 & 8.96 & 0.85 \\
\hline $\mathrm{MnO}$ & 0.16 & 0.172 & 0.025 & 0.162 & 0.001 & 0.012 & 0.004 & 0.005 & 0.001 & 0.177 & 0.046 & 0.173 & 0.009 \\
\hline $\mathrm{MgO}$ & 8.27 & 7.89 & 0.05 & 7.68 & 0.0397 & 0.239 & 0.042 & 0.264 & 0.048 & 8.16 & 0.04 & 7.95 & 0.73 \\
\hline $\mathrm{CaO}$ & 12.55 & 12.33 & 0.13 & $12.3^{d}$ & 0.0 & 16.3 & 1.0 & $16.3^{d}$ & 0.0 & 12.4 & 0.1 & $12.4^{d}$ & 0.0 \\
\hline $\mathrm{Na} 2 \mathrm{O}$ & 2.55 & 2.39 & 0.09 & 2.6 & 0.01 & 1.99 & 0.51 & 2.17 & 0.87 & 2.47 & 0.05 & 2.68 & 0.40 \\
\hline K2O & 0.08 & 0.08 & 0.01 & 0.083 & 0.001 & 0.012 & 0.008 & 0.011 & 0.004 & 0.077 & 0.021 & 0.084 & 0.004 \\
\hline P2O5 & 0.11 & 0.16 & 0.06 & & & & & & & 0.097 & 0.012 & & \\
\hline Total & 100.4 & 98.1 & & 100.20 & & 99.5 & & 100.8 & & 99.1 & & 100.3 & \\
\hline \multicolumn{14}{|l|}{$\mathrm{ppm}$} \\
\hline $\mathrm{Li}$ & & & & 5.94 & 0.64 & & & 1.44 & 0.57 & & & 6.17 & 1.69 \\
\hline $\mathrm{Be}$ & & & & 0.24 & 0.04 & & & $<2.10$ & & & & 4.20 & 3.47 \\
\hline Sc & & & & 36.8 & 0.2 & & & 0.847 & 0.167 & & & 40.8 & 0.8 \\
\hline $\mathrm{Cr}$ & & & & 301 & 6 & & & 12.51 & 4.05 & 342 & 118 & 357 & 15 \\
\hline $\mathrm{Rb}$ & & & & 0.835 & 0.022 & & & 0.425 & 0.402 & & & 0.891 & 0.109 \\
\hline $\mathrm{Sr}$ & & & & 98.9 & 0.9 & & & 156 & 11 & & & 98.6 & 1.1 \\
\hline $\mathrm{Y}$ & & & & 22.54 & 0.19 & & & 0.177 & 0.037 & & & 25.4 & 0.7 \\
\hline $\mathrm{Zr}$ & & & & 60.73 & 0.73 & & & 0.171 & 0.121 & & & 67.2 & 1.4 \\
\hline $\mathrm{Nb}$ & & & & 1.58 & 0.07 & & & 0.198 & 0.162 & & & 1.54 & 0.09 \\
\hline Cs & & & & 0.024 & 0.015 & & & 0.203 & 0.198 & & & 0.109 & 0.104 \\
\hline $\mathrm{Ba}$ & & & & 6.00 & 0.08 & & & 1.37 & 0.40 & & & 6.53 & 0.26 \\
\hline $\mathrm{La}$ & & & & 2.28 & 0.07 & & & 0.139 & 0.058 & & & 2.47 & 0.05 \\
\hline $\mathrm{Ce}$ & & & & 7.13 & 0.05 & & & 0.441 & 0.289 & & & 7.80 & 0.17 \\
\hline $\mathrm{Pr}$ & & & & 1.20 & 0.02 & & & 0.091 & 0.074 & & & 1.31 & 0.07 \\
\hline $\mathrm{Nd}$ & & & & 7.05 & 0.22 & & & 0.226 & 0.092 & & & 7.71 & 0.34 \\
\hline $\mathrm{Sm}$ & & & & 2.49 & 0.05 & & & 0.166 & 0.148 & & & 2.80 & 0.17 \\
\hline Eu & & & & 0.99 & 0.03 & & & 0.230 & 0.059 & & & 1.11 & 0.07 \\
\hline $\mathrm{Gd}$ & & & & 3.21 & 0.14 & & & 0.198 & 0.110 & & & 3.63 & 0.16 \\
\hline $\mathrm{Tb}$ & & & & 0.598 & 0.015 & & & 0.035 & 0.026 & & & 0.698 & 0.029 \\
\hline Dy & & & & 4.06 & 0.17 & & & 0.101 & 0.066 & & & 4.58 & 0.22 \\
\hline $\mathrm{Ho}$ & & & & 0.89 & 0.04 & & & 0.075 & 0.057 & & & 1.03 & 0.05 \\
\hline $\mathrm{Er}$ & & & & 2.54 & 0.12 & & & 0.068 & 0.015 & & & 2.85 & 0.17 \\
\hline $\mathrm{Tm}$ & & & & 0.361 & 0.004 & & & 0.033 & 0.027 & & & 0.409 & 0.035 \\
\hline $\mathrm{Yb}$ & & & & 2.52 & 0.09 & & & 0.122 & 0.106 & & & 2.90 & 0.22 \\
\hline Lu & & & & 0.360 & 0.008 & & & 0.033 & 0.019 & & & 0.417 & 0.029 \\
\hline $\mathrm{Hf}$ & & & & 1.60 & 0.09 & & & 0.084 & 0.037 & & & 1.93 & 0.11 \\
\hline $\mathrm{Ta}$ & & & & 0.720 & 0.026 & & & 0.066 & 0.057 & & & 0.103 & 0.020 \\
\hline $\mathrm{Pb}$ & & & & 0.189 & 0.020 & & & 0.844 & 1.326 & & & 0.444 & 0.125 \\
\hline Th & & & & 0.095 & 0.009 & & & 0.071 & 0.070 & & & 0.109 & 0.021 \\
\hline$U$ & & & & 0.050 & 0.014 & & & 0.221 & 0.157 & & & 0.058 & 0.021 \\
\hline
\end{tabular}

${ }^{a}$ Whole rock XRF (SOEST, Hawaii), EMPA (University of Vienna), LA-ICPMS (ETH Zurich), and SIMS (WHOI, Mass) measurements.

${ }^{b}$ Fused whole rock, from Table 2.

${ }^{c} n$ number of analyses; $\pm 1 \sigma$ standard deviation of the mean

${ }^{\mathrm{d}} \mathrm{CaO}$ from EMPA used as internal standard 


\section{Table 2: Experimental conditions and run products}

\begin{tabular}{|c|c|c|c|c|c|c|c|c|c|c|c|c|}
\hline \multirow[t]{2}{*}{$\begin{array}{l}\text { Run } \\
\text { no. }\end{array}$} & \multirow[t]{2}{*}{$\begin{array}{l}\text { Ramp } \\
\left({ }^{\circ} \mathrm{C} / \mathrm{hr}\right)\end{array}$} & \multirow[t]{2}{*}{$\begin{array}{c}\mathrm{T} \\
\left({ }^{\circ} \mathrm{C}\right)\end{array}$} & \multirow[t]{2}{*}{$\begin{array}{l}\text { Duration } \\
\text { (hrs) }\end{array}$} & \multirow[t]{2}{*}{$\log f_{\mathrm{O} 2}$} & \multicolumn{5}{|c|}{ Modes $^{a}$} & \multirow[t]{2}{*}{$\mathrm{Na}$ loss $^{\mathrm{b}}$} & \multirow[t]{2}{*}{$\mathrm{Fe} \operatorname{loss}^{\mathrm{D}}$} & \multirow{2}{*}{$X_{A n}{ }^{c}$} \\
\hline & & & & & $\mathrm{pl}$ & $\mathrm{sp}$ & ol & $\mathrm{cpx}$ & gl & & & \\
\hline 16 & 10 & 1220 & 99 & -11.68 & 1 & - & - & - & 99 & 33.6 & 11.0 & $0.763 \pm 7$ \\
\hline 28 & 60 & 1220 & 97 & -8.18 & $\operatorname{tr}$ & - & - & - & 99 & 5.9 & 2.1 & $0.792 \pm 3$ \\
\hline 17 & 10 & 1200 & 101 & -11.93 & 3 & - & - & $\operatorname{tr}$ & 97 & 37.5 & 4.9 & $0.757 \pm 7$ \\
\hline 31 & 60 & 1200 & 97 & -8.41 & 3 & - & - & - & 97 & 9.4 & 6.6 & $0.773 \pm 32$ \\
\hline 33 & 60 & 1200 & 97 & -0.68 & 10 & 2 & - & - & 88 & 8.2 & 3.0 & $0.767 \pm 6$ \\
\hline 35 & 60 & 1180 & 97 & -12.19 & 5 & - & - & - & 95 & 39.8 & 12.1 & $0.766 \pm 11$ \\
\hline
\end{tabular}

${ }^{a}$ Plagioclase (pl), spinel (sp), olivine (ol), clinopyroxene (cpx), glass (gl), traces (tr).

Modes (Vol \%) are calculated by non-weighted least-square mass-balance.

${ }^{\mathrm{b}}$ Relative iron and sodium loss (in oxide $1 \%$ ) estimated by non-weighted material balance calculation.

${ }^{c}$ Units after \pm represent one standard deviation of least units cited, on the base of replicate analyses.

Thus, $0.763 \pm 7$ means $0.763 \pm 0.007$. 
Table 3 : Electron microprobe (wt\%) analyses of run products

\begin{tabular}{|c|c|c|c|c|c|c|c|c|c|c|c|c|c|c|c|c|c|c|c|c|c|c|c|c|c|}
\hline Temp $\left({ }^{\circ} \mathrm{C}\right)$ & run no. & $\log \mathrm{fO}_{2}$ & Phase & $n^{A}$ & $\mathrm{SiO}_{2}$ & $\sigma$ & $\mathrm{TiO}_{2}$ & $\sigma$ & $\mathrm{Al}_{2} \mathrm{O}_{3}$ & $\sigma$ & $\mathrm{FeO}$ & $\sigma$ & MnO & $\sigma$ & $\mathrm{MgO}$ & $\sigma$ & $\mathrm{CaO}^{\mathrm{B}}$ & $\sigma$ & $\mathrm{Na}_{2} \mathrm{O}$ & $\sigma$ & $\mathrm{K}_{2} \mathrm{O}$ & $\sigma$ & $\mathbf{P}_{2} \mathbf{O}_{5}$ & $\sigma$ & Total \\
\hline \multirow[t]{6}{*}{1220} & 16 & -11.68 & $\mathrm{pl}$ & 5 & 49.98 & 0.31 & 0.05 & 0.03 & 31.62 & 0.16 & 0.30 & 0.02 & 0.03 & 0.02 & 0.28 & 0.01 & 15.26 & 0.24 & 2.61 & 0.07 & 0.02 & 0.01 & 0.04 & 0.01 & 100.15 \\
\hline & & & gl & 7 & 50.77 & 0.07 & 1.31 & 0.05 & 15.04 & 0.08 & 8.40 & 0.10 & 0.16 & 0.02 & 8.74 & 0.11 & 12.27 & 0.09 & 1.65 & 0.06 & 0.07 & 0.00 & 0.10 & 0.12 & 98.50 \\
\hline & 28 & -8.18 & $\mathrm{pl}$ & 2 & 48.09 & 0.10 & 0.05 & 0.01 & 31.34 & 0.22 & 1.07 & 0.24 & 0.02 & 0.01 & 0.23 & 0.04 & 15.92 & 0.28 & 2.31 & 0.06 & 0.01 & NA & NA & NA & 99.02 \\
\hline & & & gl & 5 & 49.80 & 0.19 & 1.23 & 0.06 & 16.13 & 0.08 & 8.64 & 0.09 & 0.18 & 0.03 & 7.54 & 0.57 & 12.33 & 0.09 & 2.34 & 0.03 & 0.08 & 0.02 & 0.08 & 0.04 & 98.43 \\
\hline & 29 & -0.68 & $\mathrm{pl}$ & 3 & 49.63 & 1.18 & 0.07 & 0.01 & 29.03 & 0.53 & 2.70 & 0.13 & 0.03 & 0.02 & 0.13 & 0.03 & 15.02 & 0.39 & 2.68 & 0.22 & 0.02 & 0.01 & NA & NA & 99.26 \\
\hline & & & gl & 5 & 50.41 & 0.25 & 1.40 & 0.04 & 14.20 & 0.08 & 8.82 & 0.05 & 0.22 & 0.02 & 9.58 & 0.37 & 12.06 & 0.16 & 2.31 & 0.07 & 0.09 & 0.03 & 0.11 & 0.01 & 99.21 \\
\hline \multirow[t]{6}{*}{1200} & 17 & -11.93 & pl & 8 & 50.06 & 0.36 & 0.05 & 0.03 & 31.35 & 0.26 & 0.32 & 0.04 & 0.01 & 0.01 & 0.31 & 0.02 & 15.16 & 0.22 & 2.67 & 0.07 & 0.03 & 0.01 & 0.09 & 0.05 & 100.00 \\
\hline & & & $\mathrm{gl}$ & 12 & 51.35 & 0.14 & 1.50 & 0.05 & 13.86 & 0.10 & 8.90 & 0.13 & 0.21 & 0.03 & 8.88 & 0.05 & 12.29 & 0.12 & 1.44 & 0.05 & 0.07 & 0.01 & 0.11 & 0.08 & 98.55 \\
\hline & 31 & -8.41 & $\mathrm{pl}$ & 6 & 49.42 & 0.48 & 0.06 & 0.01 & 30.80 & 0.20 & 1.19 & 0.06 & 0.01 & 0.00 & 0.36 & 0.11 & 15.37 & 0.20 & 2.48 & 0.43 & 0.03 & 0.01 & NA & NA & 99.72 \\
\hline & & & gl & 5 & 49.97 & 0.31 & 1.32 & 0.05 & 15.26 & 0.09 & 9.04 & 0.07 & 0.19 & 0.03 & 9.48 & 0.35 & 12.10 & 0.13 & 2.30 & 0.08 & 0.08 & 0.01 & 0.09 & 0.02 & 99.90 \\
\hline & 33 & -0.68 & $\mathrm{pl}$ & 2 & 48.84 & 0.46 & 0.07 & 0.01 & 29.75 & 0.16 & 2.41 & 0.02 & 0.02 & 0.00 & 0.47 & 0.03 & 15.35 & 0.21 & 2.55 & 0.07 & 0.03 & 0.01 & NA & NA & 99.47 \\
\hline & & & gl & 4 & 49.76 & 0.14 & 1.32 & 0.07 & 15.40 & 0.13 & 8.90 & 0.12 & 0.18 & 0.01 & 8.69 & 0.51 & 12.13 & 0.10 & 2.37 & 0.02 & 0.10 & 0.02 & 0.11 & 0.03 & 98.97 \\
\hline \multirow[t]{8}{*}{1180} & 35 & -12.19 & pl & 5 & 49.21 & 0.43 & 0.06 & 0.01 & 30.90 & 0.35 & 0.31 & 0.03 & 0.02 & 0.01 & 0.29 & 0.08 & 15.30 & 0.28 & 2.56 & 0.11 & 0.03 & 0.01 & NA & NA & 98.67 \\
\hline & & & gl & 5 & 51.78 & 0.33 & 1.41 & 0.05 & 14.82 & 0.17 & 8.71 & 0.12 & 0.20 & 0.03 & 9.31 & 0.71 & 12.30 & 0.13 & 1.49 & 0.05 & 0.08 & 0.02 & 0.02 & 0.00 & 100.16 \\
\hline & 25 & -8.65 & $\mathrm{pl}$ & 3 & 48.70 & 0.19 & 0.06 & 0.01 & 30.78 & 0.32 & 0.80 & 0.03 & 0.03 & 0.01 & 0.33 & 0.02 & 15.19 & 0.15 & 2.66 & 0.07 & 0.02 & 0.01 & NA & NA & 98.56 \\
\hline & & & gl & 5 & 50.64 & 0.49 & 1.47 & 0.07 & 14.14 & 0.09 & 9.72 & 0.12 & 0.20 & 0.03 & 9.73 & 0.74 & 12.08 & 0.11 & 2.14 & 0.05 & 0.09 & 0.02 & 0.11 & 0.04 & 100.35 \\
\hline & 34 & -8.65 & $\mathrm{pl}$ & 5 & 49.30 & 0.48 & 0.04 & 0.01 & 30.10 & 0.24 & 0.86 & 0.08 & 0.01 & 0.00 & 0.38 & 0.06 & 14.80 & 0.16 & 2.93 & 0.04 & 0.02 & 0.01 & NA & NA & 98.42 \\
\hline & & & gl & 4 & 49.81 & 0.26 & 1.42 & 0.07 & 14.51 & 0.16 & 9.63 & 0.11 & 0.19 & 0.02 & 8.68 & 0.56 & 12.18 & 0.18 & 2.21 & 0.10 & 0.08 & 0.02 & 0.10 & 0.04 & 98.87 \\
\hline & 36 & -0.68 & $\mathrm{pl}$ & 6 & 48.96 & 0.60 & 0.07 & 0.01 & 28.42 & 0.24 & 2.64 & 0.18 & 0.03 & 0.01 & 0.45 & 0.12 & 14.55 & 0.15 & 2.89 & 0.07 & 0.02 & 0.01 & NA & NA & 98.01 \\
\hline & & & gl & 5 & 51.93 & 0.23 & 1.71 & 0.09 & 13.54 & 0.08 & 8.42 & 0.09 & 0.22 & 0.03 & 9.34 & 0.50 & 11.28 & 0.15 & 2.49 & 0.11 & 0.10 & 0.02 & 0.14 & 0.04 & 99.19 \\
\hline
\end{tabular}

A number of analyses; 1 standard deviation (s.d.) of the mean

$B \quad$ Average EMP value, used as IS for the quantification of LA-ICPMS signals

NA Not Available 
Table 4: Laser Ablation ICP-MS (ppm) analyses of selected run products

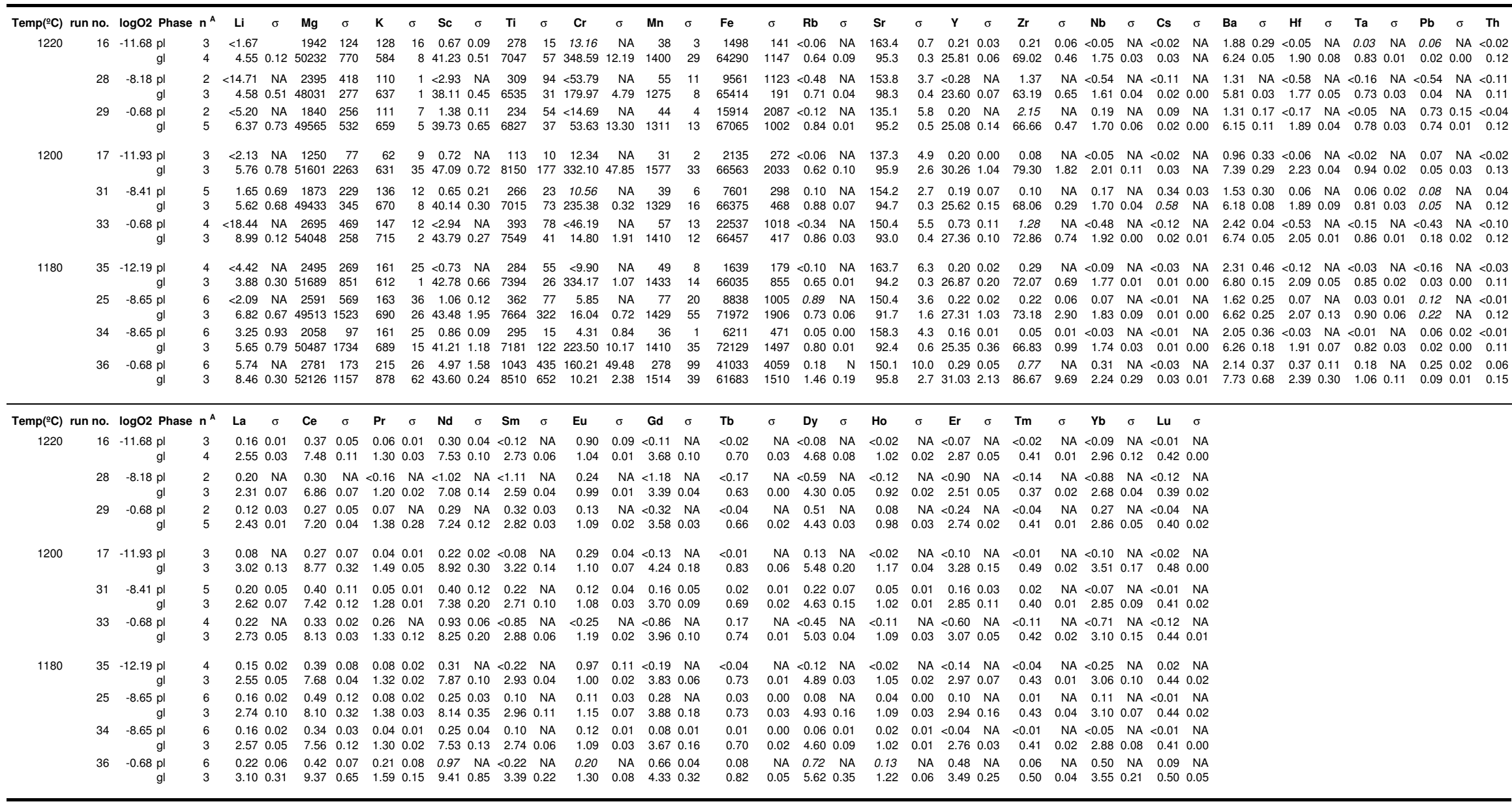

$\begin{array}{ll}\text { A } & n \text { number of analyses; } 1 \text { s.d. of the mean } \\ \text { NA Not Available; values below detection limit show as in e.g. }<1.67\end{array}$ 
Table 5: Average partition coefficients

\begin{tabular}{|c|c|c|c|c|c|c|c|c|c|c|c|c|c|c|c|c|c|c|c|c|}
\hline \multirow{4}{*}{$\begin{array}{r}\mathrm{T}^{\circ} \mathrm{C} \\
\text { Run no. } \\
\log f \mathrm{O}_{2}\end{array}$} & \multicolumn{6}{|c|}{1220} & \multicolumn{6}{|c|}{1200} & \multicolumn{8}{|c|}{1180} \\
\hline & \multirow{2}{*}{\multicolumn{2}{|c|}{$\begin{array}{c}16 \\
-11.68\end{array}$}} & \multirow{2}{*}{\multicolumn{2}{|c|}{$\begin{array}{c}28 \\
-8.18\end{array}$}} & \multirow{2}{*}{\multicolumn{2}{|c|}{$\begin{array}{c}29 \\
-0.68\end{array}$}} & \multirow{2}{*}{\multicolumn{2}{|c|}{$\begin{array}{c}17 \\
-11.93\end{array}$}} & \multirow{2}{*}{\multicolumn{2}{|c|}{$\begin{array}{l}31 \\
-8.41\end{array}$}} & \multirow{2}{*}{\multicolumn{2}{|c|}{$\begin{array}{c}33 \\
-0.68\end{array}$}} & \multirow{2}{*}{\multicolumn{2}{|c|}{$\begin{array}{c}35 \\
-12.19\end{array}$}} & \multirow{2}{*}{\multicolumn{2}{|c|}{$\begin{array}{c}25 \\
-8.65\end{array}$}} & \multirow{2}{*}{\multicolumn{2}{|c|}{$\begin{array}{c}34 \\
-8.55\end{array}$}} & \multirow{2}{*}{\multicolumn{2}{|c|}{$\begin{array}{c}36 \\
-0.68\end{array}$}} \\
\hline & & & & & & & & & & & & & & & & & & & & \\
\hline & $D^{a}$ & $\sigma^{\mathrm{b}}$ & $\mathrm{D}$ & $\sigma$ & $\mathrm{D}$ & $\sigma$ & D & $\sigma$ & $D$ & $\sigma$ & D & $\sigma$ & $D$ & $\sigma$ & $D$ & $\sigma$ & D & $\sigma$ & $D$ & $\sigma$ \\
\hline $\mathrm{Li}$ & $<0.367$ & & $<3.212$ & & $<0.816$ & & $<0.37$ & & 0.294 & 0.128 & $<2.050$ & & $<1.139$ & & $<0.306$ & & 0.575 & 0.183 & 0.678 & \\
\hline $\mathrm{Mg}$ & 0.039 & 0.003 & 0.050 & 0.009 & 0.037 & 0.005 & 0.024 & 0.005 & 0.038 & 0.005 & 0.050 & 0.009 & 0.048 & 0.005 & 0.052 & 0.012 & 0.041 & 0.002 & 0.053 & 0.004 \\
\hline $\mathrm{K}$ & 0.220 & 0.028 & 0.173 & 0.002 & 0.169 & 0.011 & 0.099 & 0.011 & 0.203 & 0.019 & 0.205 & 0.016 & 0.264 & 0.041 & 0.236 & 0.053 & 0.234 & 0.036 & 0.245 & 0.034 \\
\hline Sc & 0.016 & 0.002 & $<0.077$ & & 0.035 & 0.003 & 0.015 & 0.003 & 0.016 & 0.005 & $<0.067$ & & $<0.017$ & & 0.024 & 0.003 & 0.021 & 0.002 & 0.114 & 0.036 \\
\hline $\mathrm{Ti}$ & 0.039 & 0.002 & 0.047 & 0.014 & 0.034 & 0.008 & 0.014 & 0.008 & 0.038 & 0.003 & 0.052 & 0.010 & 0.038 & 0.007 & 0.047 & 0.010 & 0.041 & 0.002 & 0.123 & 0.052 \\
\hline $\mathrm{Cr}$ & 0.038 & & $<0.299$ & & $<0.274$ & & 0.037 & & 0.045 & & $<3.121$ & & $<0.030$ & & 0.365 & & 0.019 & 0.004 & 0.064 & 0.025 \\
\hline $\mathrm{Mn}$ & 0.027 & 0.002 & 0.043 & 0.009 & 0.034 & 0.003 & 0.020 & 0.003 & 0.029 & 0.004 & 0.040 & 0.009 & 0.034 & 0.006 & 0.054 & 0.014 & 0.026 & 0.001 & 0.184 & 0.065 \\
\hline $\mathrm{Fe}$ & 0.023 & 0.002 & 0.146 & 0.017 & 0.237 & 0.031 & 0.032 & 0.031 & 0.115 & 0.005 & 0.339 & 0.015 & 0.025 & 0.003 & 0.123 & 0.014 & 0.086 & 0.007 & 0.665 & 0.068 \\
\hline $\mathrm{Rb}$ & $<0.093$ & & $<0.676$ & & $<0.143$ & & $<0.097$ & & 0.114 & & $<0.393$ & & $<0.154$ & & 1.217 & & 0.058 & 0.003 & 0.122 & \\
\hline $\mathrm{Sr}$ & 1.715 & 0.009 & 1.565 & 0.038 & 1.420 & 0.061 & 1.431 & 0.061 & 1.629 & 0.029 & 1.617 & 0.059 & 1.738 & 0.067 & 1.640 & 0.048 & 1.714 & 0.048 & 1.568 & 0.113 \\
\hline $\mathrm{Y}$ & 0.008 & 0.001 & $<0.012$ & & 0.008 & & 0.007 & & 0.008 & 0.003 & 0.027 & 0.004 & 0.008 & 0.001 & 0.008 & 0.001 & 0.006 & 0.001 & 0.009 & 0.002 \\
\hline $\mathrm{Zr}$ & 0.003 & 0.001 & 0.022 & & 0.032 & & 0.001 & & 0.001 & & 0.018 & & 0.004 & & 0.003 & 0.001 & 0.001 & 0.000 & 0.009 & \\
\hline $\mathrm{Nb}$ & $<0.029$ & & $<0.336$ & & 0.114 & & $<0.025$ & & 0.097 & & $<0.245$ & & $<0.051$ & & 0.039 & & $<0.017$ & & 0.139 & \\
\hline Cs & $<0.771$ & & $<7.134$ & & 3.838 & & $<0.780$ & & 0.596 & & $<5.136$ & & $<3.284$ & & $<1.262$ & & $<1.074$ & & $<1.093$ & \\
\hline $\mathrm{Ba}$ & 0.301 & 0.046 & 0.226 & & 0.213 & 0.028 & 0.129 & 0.028 & 0.247 & 0.049 & 0.360 & 0.007 & 0.340 & 0.068 & 0.244 & 0.039 & 0.327 & 0.058 & 0.277 & 0.054 \\
\hline $\mathrm{La}$ & 0.065 & 0.004 & 0.084 & & 0.049 & 0.012 & 0.027 & 0.012 & 0.077 & 0.018 & 0.079 & & 0.059 & 0.008 & 0.059 & 0.009 & 0.061 & 0.009 & 0.071 & 0.021 \\
\hline $\mathrm{Ce}$ & 0.049 & 0.006 & 0.044 & & 0.037 & 0.008 & 0.031 & 0.008 & 0.054 & 0.014 & 0.040 & 0.002 & 0.051 & 0.010 & 0.061 & 0.015 & 0.045 & 0.004 & 0.045 & 0.008 \\
\hline $\mathrm{Pr}$ & 0.049 & 0.007 & $<0.133$ & & 0.053 & & 0.027 & & 0.042 & 0.005 & 0.192 & & 0.057 & 0.018 & 0.057 & 0.017 & 0.035 & 0.007 & 0.133 & 0.049 \\
\hline $\mathrm{Nd}$ & 0.040 & 0.005 & $<0.144$ & & 0.040 & & 0.025 & & 0.054 & 0.017 & 0.112 & 0.007 & 0.039 & & 0.031 & 0.004 & 0.033 & 0.006 & 0.104 & \\
\hline $\mathrm{Sm}$ & $<0.044$ & & $<0.428$ & & 0.112 & 0.010 & $<0.025$ & 0.010 & 0.081 & & $<0.295$ & & $<0.075$ & & 0.033 & & 0.037 & & $<0.065$ & \\
\hline Eu & 0.869 & 0.084 & 0.242 & 0.072 & 0.117 & & 0.260 & & 0.109 & 0.037 & $<0.211$ & & 0.966 & 0.113 & 0.098 & 0.024 & 0.112 & 0.012 & 0.156 & \\
\hline $\mathrm{Gd}$ & $<0.03$ & & $<0.348$ & & $<0.089$ & & $<0.031$ & & 0.042 & 0.012 & $<0.217$ & & $<0.05$ & & 0.071 & & 0.021 & 0.004 & 0.153 & 0.015 \\
\hline $\mathrm{Tb}$ & $<0.029$ & & $<0.268$ & & $<0.060$ & & $<0.012$ & & 0.028 & 0.010 & 0.237 & & $<0.055$ & & 0.037 & 0.004 & 0.016 & 0.003 & 0.102 & \\
\hline Dy & $<0.017$ & & $<0.137$ & & 0.115 & & 0.024 & & 0.049 & 0.016 & $<0.089$ & & $<0.0245$ & & 0.015 & & 0.012 & 0.003 & 0.128 & \\
\hline Ho & $<0.02$ & & $<0.13$ & & 0.077 & & $<0.017$ & & 0.052 & 0.008 & $<0.101$ & & $<0.019$ & & 0.041 & 0.002 & 0.020 & 0.010 & 0.106 & \\
\hline $\mathrm{Er}$ & $<0.024$ & & $<0.358$ & & $<0.088$ & & $<0.030$ & & 0.057 & 0.010 & $<0.20$ & & $<0.047$ & & 0.035 & & $<0.015$ & & 0.137 & \\
\hline Tm & $<0.049$ & & $<0.38$ & & $<0.098$ & & $<0.020$ & & 0.061 & & $<0.26$ & & $<0.093$ & & 0.033 & & $<0.025$ & & 0.122 & \\
\hline $\mathrm{Yb}$ & $<0.03$ & & $<0.328$ & & 0.093 & & $<0.028$ & & $<0.025$ & & $<0.23$ & & $<0.082$ & & 0.037 & & $<0.017$ & & 0.141 & \\
\hline $\mathrm{Lu}$ & $<0.024$ & & $<0.309$ & & $<0.101$ & & $<0.042$ & & $<0.024$ & & $<0.271$ & & 0.045 & & $<0.023$ & & $<0.024$ & & 0.190 & \\
\hline $\mathrm{Hf}$ & $<0.026$ & & $<0.328$ & & $<0.090$ & & $<0.027$ & & $<0.033$ & & $<0.259$ & & 0.057 & & 0.036 & & $<0.0157$ & & 0.153 & 0.051 \\
\hline $\mathrm{Ta}$ & 0.042 & & $<0.221$ & & $<0.064$ & & $<0.021$ & & 0.075 & 0.020 & $<0.174$ & & $<0.035$ & & 0.031 & 0.013 & $<0.012$ & & 0.170 & \\
\hline $\mathrm{Pb}$ & 2.453 & & $<12.64$ & & 0.989 & 0.200 & 1.521 & 0.200 & 1.592 & & $<2.33$ & & $<4.87$ & & 0.553 & & 2.533 & 0.697 & 2.721 & 0.485 \\
\hline Th & $<0.173$ & & $<1.016$ & & $<0.340$ & & $<0.151$ & & 0.305 & 0.081 & $<0.833$ & & $<0.270$ & & $<0.082$ & & $<0.091$ & & 0.382 & 0.259 \\
\hline U & $<0.43$ & & $<1.934$ & & $<0.182$ & & $<0.173$ & & $<0.12$ & & 0.501 & & $<0.571$ & & $<0.050$ & & $<0.198$ & & 0.105 & \\
\hline $\mathrm{Eu} / \mathrm{Sr}$ & 0.507 & 0.049 & 0.155 & 0.046 & 0.083 & 0.004 & 0.182 & & 0.067 & 0.023 & & & 0.556 & 0.068 & 0.060 & 0.015 & 0.065 & 0.007 & 0.099 & 0.007 \\
\hline $\mathrm{Fe} / \mathrm{Mg}$ & 0.60 & 0.07 & 2.93 & 0.62 & 6.39 & 1.23 & 1.32 & 1.32 & 3.02 & 0.39 & 6.80 & 1.22 & 0.51 & 0.08 & 2.35 & 0.59 & 2.11 & 0.21 & 12.47 & 1.52 \\
\hline
\end{tabular}

a upper limits are based on $3 \sigma$

${ }^{b}$ error on $D_{i}$ given as $1 \sigma$ whenever calculation was possible 


\section{Table 6: Fit parameters from Lattice Strain Model}

\begin{tabular}{l|cccccc}
\hline Run no & 31 QFM & 35 IW & 34 QFM & 36 AIR & 16 IW & 17 IW \\
\hline valence & $2+$ & $2+$ & $2+$ & $2+$ & $2+$ & $2+$ \\
$\mathrm{D}_{0}$ & $1.82(3)$ & $1.827(2)$ & $1.867(4)$ & $1.795(4)$ & $1.833(9)$ & $1.73(5)$ \\
$\mathrm{E}_{0}$ & $120(5)$ & $104(1)$ & $113(3)$ & $108(3)$ & $110(2)$ & $140(6)$ \\
$\mathrm{r}_{0}$ & $1.212(2)$ & $1.225(1)$ & $1.219(3)$ & $1.212(4)$ & $1.220(1)$ & $1.203(3)$ \\
\hline valence & $3+$ & $3+$ & $3+$ & $3+$ & $3+$ & $3+$ \\
$\mathrm{D}_{0}$ & nd & $0.058(7)$ & nd & nd & $0.079(29)$ & $0.029(1)$ \\
$\mathrm{E}_{0}$ & nd & $296(202)$ & nd & nd & $172(77)$ & $282(79)$ \\
$\mathrm{r}_{0}$ & nd & $1.163(29)$ & nd & nd & $1.219(58)$ & $1.145(11)$ \\
\hline
\end{tabular}

All calculations made for plagioclase A-site.

Values in parentheses are 1 s.d. uncertainties on the fit parameters in terms of least significant figures

$\mathrm{D}_{0}$ : strain-compensated partition coefficient

$\mathrm{E}$ : Young Modulus of the lattice site (in GPa)

$r_{0}$ : optimum site radius (in $\AA$ ) 